Check for updates

Cite this: J. Mater. Chem. C, 2021 , 9, 1657

Received 11th July 2020 ,

Accepted 4th September 2020

DOI: $10.1039 / \mathrm{dOtc03277h}$

rsc.li/materials-c

\section{Electronic and crystal structure of bi-intercalated titanium diselenide $\mathrm{Cu}_{x} \mathrm{Ni}_{y} \mathrm{TiSe}_{2} \dagger$}

\author{
E. G. Shkvarina, (D) ${ }^{a}$ A. I. Merentsov, ${ }^{a}$ M. S. Postnikov, ${ }^{a}$ A. S. Shkvarin, (D) *a \\ S. V. Pryanichnikov, ${ }^{b}$ I. Pišs, (DD ${ }^{c d}$ S. Nappini, (DD ${ }^{d}$ F. Bondino (D) ${ }^{d}$ and A. N. Titov $\mathbb{D}^{a}$
}

A comprehensive study of the crystal and electronic structure of $\mathrm{TiSe}_{2}$ intercalated with two $3 \mathrm{~d}$ metals, $\mathrm{Cu}$ and $\mathrm{Ni}$, is presented. It is found that the intercalation of $\mathrm{Cu}$ into $\mathrm{Ni}_{x} \mathrm{TiSe}_{2}$ at room temperature leads to the displacement of the $\mathrm{Ni}$ atoms from the octahedral to tetrahedral sites with respect to the $\mathrm{Se}$ sublattice. This effect is explained by the charge transfer from $\mathrm{Cu}$ to the $\mathrm{TiSe}_{2}$-derived conduction band, which makes the chemical bond of $\mathrm{Ni}$ with the lattice more stable. This is because the hybridization between $\mathrm{Ni} 3 \mathrm{~d}$ and $\mathrm{Se} 4 \mathrm{p}, 4 \mathrm{~s}$ states is stronger than that between $\mathrm{Ni} 3 \mathrm{~d}$ and $\mathrm{Ti} 3 \mathrm{~d}$ in mono-intercalated $\mathrm{Ni}_{x} \mathrm{TiSe}_{2}$. Therefore, it is possible to control the type of the coordination of the intercalated transition metal atom by changing the concentration of doped electrons.

\section{Introduction}

Titanium dichalcogenides $\mathrm{TiCh}_{2}(\mathrm{Ch}=\mathrm{S}$, Se, Te $)$ have been studied for a long time. ${ }^{1-6}$ The intercalation of $3 \mathrm{~d}$ transition metals into $\mathrm{TiCh}_{2}$ alters significantly the physical properties and electronic structure of these materials. ${ }^{7-10}$ To date, the effect of intercalation on the electronic structure of layered transition metal dichalcogenides is well understood. However, there is little research on the formation of materials intercalated by several different metals simultaneously. A strong magnetic and, possibly, chemical interaction between intercalated $\mathrm{Co}$ and $\mathrm{Fe}$ in $\mathrm{TiS}_{2}$ was reported in ref. 11. It has been shown that the intercalation of $0.5 \mathrm{~mol} \% \mathrm{Fe}$ into $\mathrm{Co}_{0.25} \mathrm{TiS}_{2}$ changes the character of the magnetic ordering from ferromagnetic (or ferrimagnetic) to antiferromagnetic. Such a small concentration means that the change of the magnetic ordering is due to the interaction between the Fe and Co atoms via the host lattice.

On the other hand, an influence of co-intercalation in $(\mathrm{Cr}, \mathrm{Ni})_{1 / 3} \mathrm{TaS}_{2}$ on the physical properties of the material has not been observed. ${ }^{12}$ This difference may be the result of the different electronic structure of the $\mathrm{TiS}_{2}$ and $\mathrm{TaS}_{2}$ host lattices. Indeed, the electronic configuration of $\mathrm{Ti}$ in $\mathrm{TiCh}_{2}, \mathrm{Ch}=\mathrm{S}$, Se, Te, can be described as $\mathrm{d}^{0}$, while $\mathrm{Ta}$ in $\mathrm{TaCh}_{2}$ has the $\mathrm{d}^{1}$

\footnotetext{
${ }^{a}$ Institute of Metal Physics, Russian Academy of Sciences-Ural Division, 620990 Yekaterinburg, Russia. E-mail: shkvarin@imp.uran.ru

${ }^{b}$ Institute of Metallurgy, Ural Branch of Russian Academy of Sciences, 620016, Yekaterinburg, Russia

${ }^{c}$ Elettra - Sincrotrone Trieste S.C.p.A., S.S. 14 km 163.5, 34149 Basovizza, Trieste, Italy

${ }^{d}$ IOM-CNR, Laboratorio TASC, S.S. 14-km 163.5, 34149 Basovizza, Trieste, Italy

$\dagger$ Electronic supplementary information (ESI) available. See DOI: 10.1039/d0tc03277h
}

configuration. This results in the location below the Fermi level of the $\mathrm{M}$ states in $\mathrm{M}_{x} \mathrm{TaCh}_{2}$ and directly at the Fermi level in $\mathrm{M}_{x} \mathrm{TiCh}_{2}$. Since it is the states at the Fermi level that are predominantly responsible for the character of the chemical bond, the co-intercalation effect in $\mathrm{TiCh}_{2}$ should be visible more clearly. Little is known about $\mathrm{Cu}_{x} \mathrm{Fe}_{y} \mathrm{TiSe}_{2},{ }^{13,14}$ although the crystal structure and thermodynamic stability in a wide temperature range were studied for this system. It has been shown that the subsystems of $\mathrm{Fe}$ and $\mathrm{Cu}$ are independent. $\mathrm{Cu}_{x} \mathrm{M}_{0.25} \mathrm{TiSe}_{2}(\mathrm{M}=\mathrm{Mn}, \mathrm{Co}$, and $\mathrm{Ni}$ ) co-intercalated compounds were previously investigated by our group. ${ }^{15}$ However, the research was focused on the lattice parameters and thermodynamic stability only.

It should be noted that the synthesis of all the above mentioned co-intercalated materials was performed at high temperature. This provides the equilibrium for both the sublattices of intercalated metals and the whole crystal lattice. However, the properties of the co-intercalated $\mathrm{TiCh}_{2}$ are likely influenced by the charge transfer, mutual influence of the intercalated metals, their interaction with the host lattice and magnetic interaction. In this study, we focus on $\mathrm{Ni}$ and $\mathrm{Cu}$ co-intercalation in $\mathrm{TiSe}_{2}$; the possibility of co-intercalation of these metals was reported in ref. 15 . Since $\mathrm{Cu}$ can be intercalated into $\mathrm{TiSe}_{2}$ at room temperature, ${ }^{16}$ this provides minimal distortion of the host lattice and the Ni sublattice, but the possibility of charge transfer is preserved. In addition, both $\mathrm{Cu}$ in $\mathrm{Cu}_{x} \mathrm{TiSe}_{2}$ and $\mathrm{Ni}$ in $\mathrm{Ni}_{x} \mathrm{TiSe}_{2}$ intercalation compounds occupy the same positions in the van der Waals gap, which are octahedrally coordinated by chalcogen. Therefore, a competition for the occupation of these positions can be expected.

The crystal structure of the $\mathrm{TiSe}_{2}$-based intercalation compound is shown in Fig. 1. Two types of positions in the 


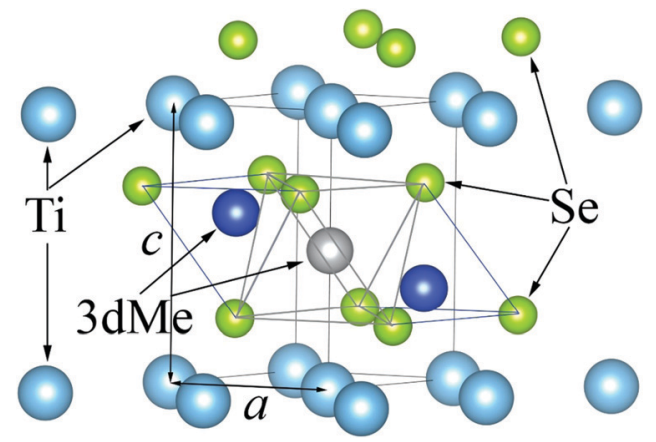

Fig. 1 Fragment of $\mathrm{M}_{x} \mathrm{TiSe} \mathrm{S}_{2}$ crystal structure. The tetrahedral sites are shown as two blue spheres and the octahedral site is shown as a gray sphere.

$\mathrm{TiSe}_{2}$ interlayer space are available for intercalated metals with respect to the Se sublattice: octahedral (shown in gray) and tetrahedral (shown in blue) sites. In all TiSe ${ }_{2}$-based compounds intercalated by noble and transition metals, intercalated atoms are located in octahedral sites.

This study is focused on the synthesis and systematic study of the crystal and electronic structures of the co-intercalated $\mathrm{Cu}_{x} \mathrm{Ni}_{y} \mathrm{TiSe}_{2}$ compound to clarify the mutual influence of the intercalated metals.

\section{Experiment}

The polycrystalline phase of $\mathrm{Cu}_{x} \mathrm{Ni}_{y} \mathrm{TiSe}_{2}$ was synthesized by $\mathrm{Ni}$ intercalation into $\mathrm{TiSe}_{2}$ followed by $\mathrm{Cu}$ intercalation into $\mathrm{Ni}_{y} \mathrm{TiSe}_{2}$. The synthesis procedures for $\mathrm{TiSe}_{2}$ as well as for $\mathrm{Ni}$ intercalation into $\mathrm{TiSe}_{2}$ are described in detail elsewhere. ${ }^{15} \mathrm{Cu}$ intercalation was performed at room temperature by the method described in ref. 16. The $\mathrm{Cu}_{x} \mathrm{Ni}_{0.1} \mathrm{TiSe}_{2}$ and $\mathrm{Cu}_{x} \mathrm{Ni}_{0.25} \mathrm{TiSe}_{2}$ systems (see $\mathrm{Cu}$ concentrations $x$ in Tables 1-3) were successfully synthesized. An increase in the Ni concentration to $50 \mathrm{~mol} \%$ led to a crumbling of the samples into powder. The contact area between grains became smaller and, consequently, the homogeneous state was not achieved. The only exceptions were the $\mathrm{Cu}_{0.1} \mathrm{Ni}_{0.5} \mathrm{TiSe}_{2}$ and $\mathrm{Cu}_{0.5} \mathrm{Ni}_{0.5} \mathrm{TiSe}_{2}$ compounds.

The homogeneity of the samples was checked by X-ray diffraction analysis. Crystal structure and phase composition were determined using X-ray powder diffraction on a Shimadzu XRD 7000 Maxima diffractometer $\left(\mathrm{Cu} \mathrm{K} \alpha_{1}\right.$ radiation, graphite monochromator, $2 \Theta=12-92, \Delta \Theta=0.02$, exposure time $1.2 \mathrm{~s}$ ). The diffraction patterns contained only peaks of the main phase and those of metallic copper (which is not surprising, because the synthesis was carried out at room temperature). The crystal structure refinement was performed using GSAS (General Structure Analysis System) software. ${ }^{17}$ The chemical compositions of the obtained intercalation compounds are summarized in Tables 1-3.

The single crystals for the soft X-ray spectroscopy measurements were grown from the powdered $\mathrm{Cu}_{x} \mathrm{Ni}_{y} \mathrm{TiSe}_{2}$ materials using the gas transport reaction technique in evacuated quartz ampoules with $I_{2}$ as the gas carrier. ${ }^{18}$ The single crystals had a shape of thin plates approximately $2-3 \mathrm{~mm}$ large and $0.05 \mathrm{~mm}$ thick. Two crystals with the composition of $\mathrm{Cu}_{0.13} \mathrm{Ni}_{0.43} \mathrm{TiSe}_{2}$ and $\mathrm{Cu}_{0.2} \mathrm{Ni}_{0.25} \mathrm{TiSe}_{2}$ were grown for this work. In addition to the co-intercalated crystals, mono-intercalated $\mathrm{Ni}_{x} \mathrm{TiSe}_{2}$ $(x=0.14,0.46)$ and $\mathrm{Cu}_{x}$ TiSe $2(x=0.09,0.33)$ single crystals were investigated too. Details of their synthesis have been reported elsewhere. ${ }^{19,20}$

The synchrotron radiation X-ray photoelectron (XPS), X-ray absorption (XAS) and resonant X-ray photoelectron (ResPES) spectra for $\mathrm{Ni}_{0.14} \mathrm{TiSe}_{2}, \mathrm{Cu}_{0.13} \mathrm{Ni}_{0.43} \mathrm{TiSe}_{2}$ and $\mathrm{Cu}_{0.2} \mathrm{Ni}_{0.25} \mathrm{TiSe}_{2}$ were obtained on the CNR IOM BACH beamline ${ }^{21}$ at the Elettra synchrotron facility (Trieste, Italy). Linearly-polarized X-rays with a polarization vector $60^{\circ}$ off the surface plane were used. All the samples were cleaved in situ at room temperature in a vacuum chamber with a base pressure lower than $1 \times 10^{-9}$ Torr. The purity of the surface was confirmed by the absence of oxygen and carbon peaks in the XPS survey spectra. XPS spectra were acquired using a VG-Scienta R3000 hemispherical analyzer at an angle of $60^{\circ}$ with respect to the X-ray incidence beam. The Ti $2 \mathrm{p}$, Se $3 d, \mathrm{Ni} 2 \mathrm{p}$ and $\mathrm{Cu} 2 \mathrm{p}$ core levels were measured at normal emission angle using $1114 \mathrm{eV}$ excitation energy. The total energy resolution for the core level and valence band spectra was $0.4 \mathrm{eV}$. The binding energies were calibrated with respect to the $\mathrm{Au} 4 \mathrm{f}_{7 / 2}$ $\left(E_{\mathrm{B}}=84.0 \mathrm{eV}\right)$ signal from a gold reference sample. ResPES spectra were acquired by measuring sets of valence band spectra at photon energies corresponding to the resonances at the $\mathrm{Ti} \mathrm{L}_{3}$ and $\mathrm{Ni} \mathrm{L}_{3}$ edges. $\mathrm{Ni}$ and $\mathrm{Ti} \mathrm{L}_{3,2}$ XAS spectra were acquired in total electron yield mode. The photon energy resolution was

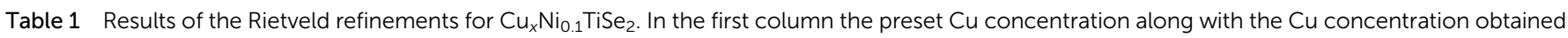
from the refinement result (in brackets) are listed

\begin{tabular}{|c|c|c|c|c|c|c|c|c|c|c|c|}
\hline$x$ & $a, \AA$ & $c, \AA$ & $Z \mathrm{Se}$ & $\begin{array}{l}\text { Frac. Ni } \\
\left(\begin{array}{lll}0 & 0 & 1 / 2\end{array}\right)\end{array}$ & $\begin{array}{l}\text { Frac. Ni } \\
(1 / 32 / 3 z)\end{array}$ & $\begin{array}{l}Z \mathrm{Ni} \\
(1 / 32 / 3 z)\end{array}$ & $\begin{array}{l}\text { Frac. Cu } \\
\left(\begin{array}{lll}0 & 0 & 1 / 2\end{array}\right)\end{array}$ & $\begin{array}{l}\text { Frac. } \mathrm{Cu} \\
(1 / 32 / 3 z)\end{array}$ & $Z \mathrm{Cu}$ & $R_{\mathrm{F}}^{2}, \%$ & $\chi^{2}$ \\
\hline $0.05(0.011)$ & $3.540(1)$ & $5.960(1)$ & $0.2613(2)$ & 0.1 & 0 & - & 0.011 & 0 & - & 6.36 & 2.515 \\
\hline $0.1(0.069)$ & $3.541(1)$ & $5.961(1)$ & $0.2605(2)$ & $0.047(4)$ & $0.027(2)$ & $0.47(1)$ & 0.069 & 0 & - & & \\
\hline $0.15(0.108)$ & $3.541(1)$ & $5.961(2)$ & $0.2596(2)$ & $0.009(1)$ & $0.045(2)$ & $0.456(6)$ & 0.108 & 0 & - & 3.01 & 2.528 \\
\hline $0.2(0.128)$ & $3.541(1)$ & $5.961(1)$ & $0.2598(2)$ & $0.003(4)$ & $0.048(2)$ & $0.468(6)$ & $0.122(3)$ & $0.003(1)$ & $0.64(6)$ & 4.34 & 2.815 \\
\hline $0.25(0.184)$ & $3.540(1)$ & $5.961(1)$ & $0.2587(2)$ & 0 & 0.05 & $0.430(5)$ & $0.127(4)$ & $0.028(2)$ & $0.496(9)$ & 2.72 & 2.420 \\
\hline $0.3(0.260)$ & $3.542(1)$ & $5.962(1)$ & $0.2558(2)$ & 0 & 0.05 & $0.435(5)$ & $0.150(3)$ & $0.055(2)$ & $0.613(3)$ & 4.40 & 2.834 \\
\hline $0.35(0.270)$ & $3.543(1)$ & $5.962(1)$ & $0.2558(2)$ & 0 & 0.05 & $0.399(5)$ & $0.162(3)$ & $0.054(2)$ & $0.623(3)$ & 5.70 & \\
\hline $0.4(0.307)$ & $3.543(1)$ & $5.962(1)$ & $0.2530(2)$ & 0 & 0.05 & $0.367(6)$ & $0.163(3)$ & $0.072(2)$ & $0.652(3)$ & 8.57 & 2.817 \\
\hline $0.45(0.341)$ & $3.542(1)$ & $5.961(1)$ & $0.2522(3)$ & 0 & 0.05 & $0.420(6)$ & $0.185(3)$ & $0.078(2)$ & $0.654(3)$ & 7.99 & 3.476 \\
\hline $0.5(0.303)$ & $3.540(1)$ & $5.963(1)$ & $0.2556(2)$ & 0 & 0.05 & $0.402(6)$ & $0.169(4)$ & $0.067(2)$ & $0.630(3)$ & 6.15 & 3.035 \\
\hline
\end{tabular}


Table 2 Results of the Rietveld refinements for $\mathrm{Cu}_{x} \mathrm{Ni}_{0.25} \mathrm{TiSe}_{2}$. In the first column the preset $\mathrm{Cu}$ concentration along with the Cu concentration obtained from the refinement result (in brackets) are listed

\begin{tabular}{|c|c|c|c|c|c|c|c|c|c|c|c|}
\hline$x$ & $a, \AA$ & $c, \AA$ & $Z \mathrm{Se}$ & $\begin{array}{l}\text { Frac. } \mathrm{Ni} \\
\left(\begin{array}{lll}0 & 0 & 1 / 2\end{array}\right)\end{array}$ & $\begin{array}{l}\text { Frac. Ni } \\
(1 / 32 / 3 z)\end{array}$ & $\begin{array}{l}Z \mathrm{Ni} \\
(1 / 32 / 3 z)\end{array}$ & $\begin{array}{l}\text { Frac. Cu } \\
\left(\begin{array}{lll}0 & 0 & 1 / 2\end{array}\right)\end{array}$ & $\begin{array}{l}\text { Frac. } \mathrm{Cu} \\
(1 / 3 \quad 2 / 3 z)\end{array}$ & $Z \mathrm{Cu}$ & $R_{\mathrm{F}}^{2}, \%$ & $\chi^{2}$ \\
\hline $0.05(0.05)$ & $3.548(1)$ & $5.922(1)$ & $0.2601(2)$ & $0.210(4)$ & $0.020(2)$ & $0.47(1)$ & 0.05 & 0 & - & 3.98 & 2.889 \\
\hline $0.3(0.258)$ & $3.549(1)$ & $5.922(1)$ & $0.2574(2)$ & $0.119(4)$ & $0.065(2)$ & $0.453(4)$ & $0.166(3)$ & $0.046(2)$ & $0.637(4)$ & 5.62 & 2.768 \\
\hline $0.35(0.273)$ & $3.549(1)$ & $5.922(1)$ & $0.2562(3)$ & $0.072(4)$ & $0.089(2)$ & $0.435(3)$ & $0.181(4)$ & $0.046(2)$ & $0.658(5)$ & 5.45 & 3.045 \\
\hline $0.4(0.365)$ & $3.549(1)$ & $5.923(1)$ & $0.2519(2)$ & $0.045(4)$ & $0.103(2)$ & $0.396(2)$ & $0.245(3)$ & $0.060(2)$ & $0.639(3)$ & 7.07 & 3.327 \\
\hline
\end{tabular}

Table 3 Results of the Rietveld refinements for $\mathrm{Cu}_{x} \mathrm{Ni}_{0.5} \mathrm{TiSe}_{2}$

\begin{tabular}{|c|c|c|c|c|c|c|c|c|c|c|c|}
\hline$x$ & $a, \AA$ & $c, \AA$ & $Z \mathrm{Se}$ & $\begin{array}{l}\text { Frac. } \mathrm{Ni} \\
\left(\begin{array}{lll}0 & 0 & 1 / 2\end{array}\right)\end{array}$ & $\begin{array}{l}\text { Frac. Ni } \\
(1 / 32 / 3 z)\end{array}$ & $\begin{array}{l}Z \mathrm{Ni} \\
(1 / 32 / 3 z)\end{array}$ & $\begin{array}{l}\text { Frac. Cu } \\
\left(\begin{array}{lll}0 & 0 & 1 / 2\end{array}\right)\end{array}$ & $\begin{array}{l}\text { Frac. Cu } \\
(1 / 3 \quad 2 / 3 z)\end{array}$ & $Z \mathrm{Cu}$ & $R_{\mathrm{F}}^{2}, \%$ & $\chi^{2}$ \\
\hline $0.1(0.1)$ & $3.566(1)$ & $5.928(1)$ & $0.2600(2)$ & $0.377(4)$ & $0.061(2)$ & $0.429(3)$ & 0.1 & 0 & - & 4.47 & 2.587 \\
\hline $0.5(0.5)$ & $3.566(1)$ & $5.929(1)$ & $0.2438(2)$ & $0.151(5)$ & $0.175(3)$ & $0.471(1)$ & 0.5 & 0 & - & 6.55 & 2.379 \\
\hline
\end{tabular}

set to $0.06 \mathrm{eV}$ at $\mathrm{Ti}$ L-edge and $0.2 \mathrm{eV}$ at $\mathrm{Cu}$ and $\mathrm{Ni}$ L-edge, respectively. The photon energy scale was calibrated with an accuracy of $0.1 \mathrm{eV}$ using $\mathrm{Au} 4 \mathrm{f}$ XPS spectra measured with the fundamental and second harmonic of the monochromator. The uncertainty in Ni L-edge calibration is $0.2-0.3 \mathrm{eV}$.

The XPS and XAS spectra for $\mathrm{Cu}_{x} \mathrm{TiSe}_{2}(x=0.09,0.33)$ were obtained on the Russian-German beamline at the BESSY II synchrotron (Berlin, Germany). The Ti 2 p, Se $3 \mathrm{~d}$ and $\mathrm{Cu} 2 \mathrm{p}$ core levels were measured at normal emission angle at $800 \mathrm{eV}$ excitation energy. The total resolution was approximately $0.2 \mathrm{eV}$. The binding energies were calibrated with respect to the $\mathrm{Pt} 4 \mathrm{f}_{7 / 2}\left(E_{\mathrm{B}}=71.2 \mathrm{eV}\right)$ signal from a platinum reference sample. All measurements were performed at room temperature.

The XPS and XAS spectra for $\mathrm{Ni}_{0.46} \mathrm{TiSe}_{2}$ sample were obtained on the CiPo beamline at the Elettra synchrotron facility. All measurements were performed at room temperature.

The fitting procedure for the XPS spectra was performed using KolXPD software. ${ }^{22}$

\section{Results}

\section{Crystal structure}

Following the approach introduced in ref. 15 the crystal structure of $\mathrm{Cu}_{x} \mathrm{Ni}_{y} \mathrm{TiSe}_{2}$ was refined in the space group $P \overline{3} m 1$ (No.

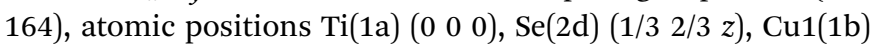
(0 0 1/2) (octahedral sites), Cu2(2d) (1/3 2/3 z) (tetrahedral sites), Ni1(1b) (lo 0 1/2) (octahedral sites), Ni2(2d) (1/3 2/3 z) (tetrahedral sites). ${ }^{23}$ Site occupancy fractions (SOF) for $\mathrm{Ni}(1 \mathrm{~b})$ and $\mathrm{Ni}$ (2d) were constrained by total Ni concentration, considering the multiplicity of the positions. The same constraint was used for SOFs for $\mathrm{Cu}(1 \mathrm{~b})$ and $\mathrm{Cu}(2 \mathrm{~d})$. The background was approximated by Chebyshev polynomials with 16 coefficients.

Some X-ray diffraction patterns contained peaks from metallic copper besides the peaks from the main phase. To take this into account, the metallic copper was included into the crystal structure refinement. The fraction of this phase, determined from the refinement, was used to define real $\mathrm{Cu}$ content in the intercalation phase (these values are given in brackets in $x$ columns, Tables 1-3). After that, this $\mathrm{Cu}$ content in the intercalation phase was fixed and distributed over the $1 \mathrm{~b}$ and $2 \mathrm{~d} \mathrm{Cu}$ sites. Therefore, when $\mathrm{Cu}$ occupied only one of these sites, the corresponding SOF was taken from the weight fraction for the metallic $\mathrm{Cu}$ phase and the error bars for the $\mathrm{Cu} 1 \mathrm{~b}$ SOF in these cases are not given. The lattice parameters $a$ and $c$ change only slightly when $\mathrm{Cu}$ is intercalated into $\mathrm{Ni}_{y} \mathrm{TiSe}_{2}$ (see Fig. 2 and Tables 1-3). The changes induced by $\mathrm{Cu}$ intercalation into $\mathrm{Ni}_{y} \mathrm{TiSe}_{2}$ are 2 orders of magnitude weaker than that determined by the same amount of $\mathrm{Ni}$.

Fig. 3 shows the distribution of the $\mathrm{Cu}$ and $\mathrm{Ni}$ atoms over the octahedral (1b) and tetrahedral (2d) sites in the interlayer space

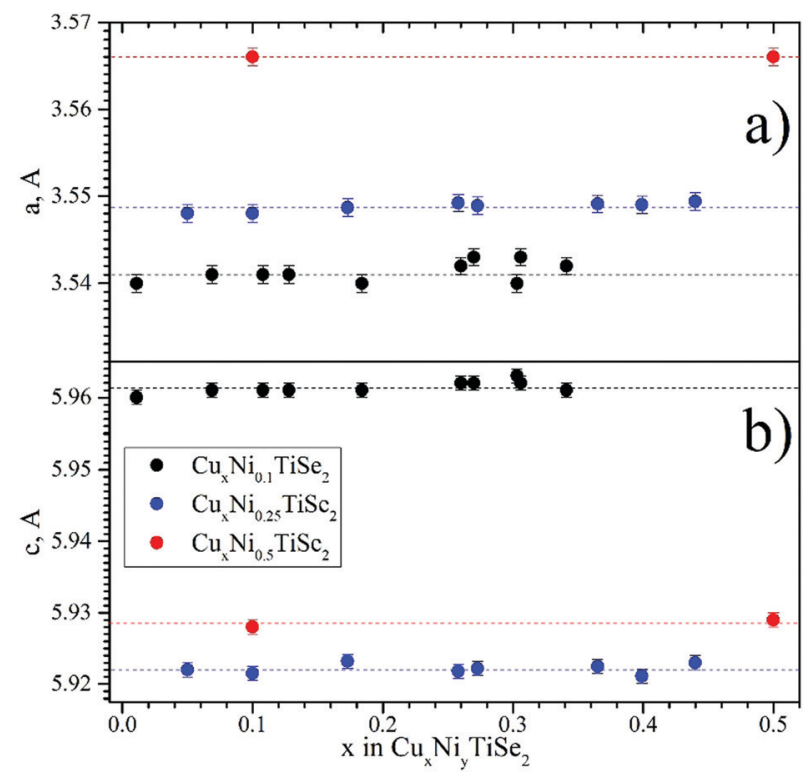

Fig. 2 Lattice parameters (a - panel a; $c$ - panel b) for $\mathrm{Cu}_{x} \mathrm{Ni}_{y} \mathrm{TiSe}_{2}$ obtained from $\mathrm{X}$-ray powder diffraction. 

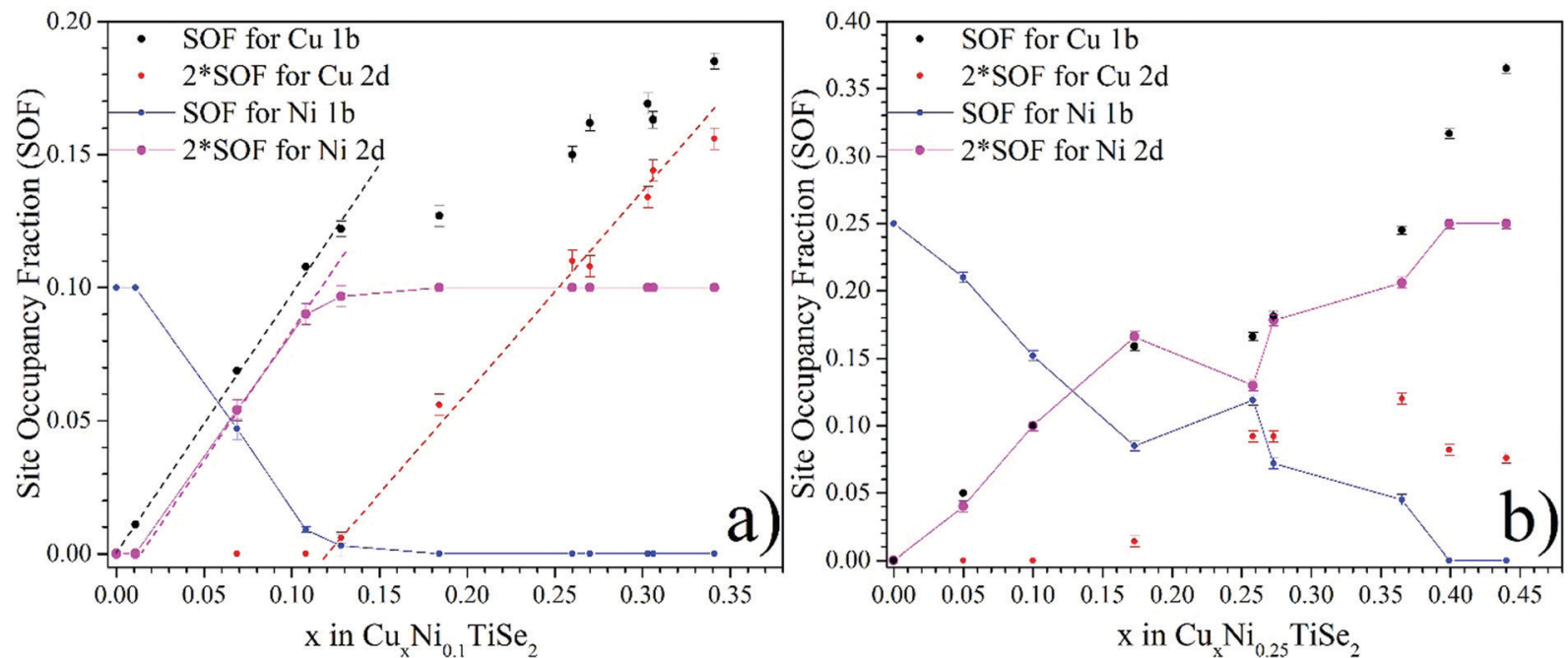

Fig. 3 Occupation of the octahedral and tetrahedral sites ( $1 \mathrm{~b}$ - octahedral sites, $2 \mathrm{~d}$ - tetrahedral sites) in the interlayer space by the Ni and $\mathrm{Cu}$ atoms for $\mathrm{Cu}_{x} \mathrm{Ni}_{y} \mathrm{TiSe}_{2}(y=0.1$ - panel a, $y=0.25$ - panel b).

for $\mathrm{Cu}_{x} \mathrm{Ni}_{0.1} \mathrm{TiSe}_{2}$ (panel a) and $\mathrm{Cu}_{x} \mathrm{Ni}_{0.25} \mathrm{TiSe}_{2}$ (panel b). Since the lattice parameters change slightly, it is expected that the main changes in the crystal structure will be associated with a change in the type of crystallographic sites occupied by the intercalated atoms.

In both $\mathrm{Cu}_{x} \mathrm{Ni}_{0.25} \mathrm{TiSe}_{2}$ and $\mathrm{Cu}_{x} \mathrm{Ni}_{0.1} \mathrm{TiSe}_{2}$, the $\mathrm{Cu}$ intercalation leads to the displacement of the $\mathrm{Ni}$ atoms from the octahedral to tetrahedral sites. However, for $\mathrm{Cu}_{x} \mathrm{Ni}_{0.1} \mathrm{TiSe}_{2}$ compounds in the $\mathrm{Cu}$ concentration range of $0<x<0.013$ $\mathrm{Cu}$ intercalation does not change the $\mathrm{Ni}$ coordination (see. Fig. 3, panel a). Therefore, it can be assumed that for $\mathrm{Cu}_{x} \mathrm{Ni}_{0.1} \mathrm{TiSe}_{2}$ the interaction between $\mathrm{Ni}$ and $\mathrm{Cu}$ atoms is negligible in the $\mathrm{Cu}$ concentration range of $0<x<0.013$. For $\mathrm{Cu}$ concentrations of $0.013<x<0.12$ in $\mathrm{Cu}_{x} \mathrm{Ni}_{0.1} \mathrm{TiSe}_{2}$ and $0<x<0.17$ in $\mathrm{Cu}_{x} \mathrm{Ni}_{0.25} \mathrm{TiSe}_{2}$, almost all $\mathrm{Cu}$ atoms occupy octahedral sites and each $\mathrm{Cu}$ atom displaces one $\mathrm{Ni}$ atom from the octahedral to tetrahedral site (Fig. 3, panel b).

The diffraction pattern for $\mathrm{Ni}_{0.5} \mathrm{TiSe}_{2}$ contains extra peaks indicating the monoclinic $I 2 / \mathrm{m}$ ordering, as it has been observed previously. ${ }^{24}$ However, even $10 \mathrm{~mol} \% \mathrm{Cu}$ in $\mathrm{Cu}_{0.1} \mathrm{Ni}_{0.5} \mathrm{TiSe}_{2}$ turns the crystal structure to the trigonal $P \overline{3} m 1$ one (see ESI $\dagger$ ). Obviously, the disordering of the intercalated atoms is caused by the displacement of the $\mathrm{Ni}$ atoms in the tetrahedral sites, while monoclinic ordering requires the occupation of just the octahedral sites.

The $\mathrm{Cu}$ intercalation leads to a linear increase in the total occupation of the tetrahedral sites with both $\mathrm{Cu}$ and $\mathrm{Ni}$ atoms (Fig. 4). At the $\mathrm{Cu}_{0.33} \mathrm{Ni}_{0.25} \mathrm{TiSe}_{2}$ composition, this value reaches saturation and corresponds to the total occupation of the tetrahedral sites, which is equal to 0.33 (considering the multiplicity $2 \times 0.165$ ). This means that one-third of the unit cells contains one intercalated atom in the tetrahedral site. In its turn, this corresponds to the maximum occupation of the tetrahedral sites by both $\mathrm{Cu}$ and $\mathrm{Ni}$ atoms. Moreover, in the $\mathrm{Cu}$ concentration range of $0.05 \leq x \leq 0.15$ in $\mathrm{Cu}_{x} \mathrm{Ni}_{0.25} \mathrm{TiSe}_{2}$ the tetrahedral sites are initially occupied by the $\mathrm{Ni}$ atoms only but starting from $x=0.25$ the $\mathrm{Cu}$ atoms begin to occupy the tetrahedral sites too. In the $\mathrm{Cu}$ concentration range of $0.25 \leq$ $x \leq 0.45 \mathrm{Cu}$ SOF for the tetrahedral sites does not change significantly, but the $\mathrm{Ni}$ atoms are gradually and at $x=0.45$ completely displaced to the tetrahedral sites (Fig. 4, panel b).

For the $\mathrm{Cu}_{x} \mathrm{Ni}_{0.1} \mathrm{TiSe}_{2}$ system, the total occupation of the tetrahedral sites also increases, but the saturation is not achieved, because the total concentration of the intercalated atoms $(\mathrm{Cu}+\mathrm{Ni})$ is less than the saturation value of $x+y=0.33$ (see Fig. 4, panel a). But in this case the tetrahedral sites are initially occupied only by the $\mathrm{Ni}$ atoms until their complete displacement by the $\mathrm{Cu}$ atoms. At $x>0.13$ the $\mathrm{Cu}$ atoms begin to occupy the tetrahedral sites too. The data for the $\mathrm{Cu}_{0.5} \mathrm{Ni}_{0.5} \mathrm{TiSe}_{2}$ sample confirms this conclusion: the tetrahedral sites, in this case, are occupied by Ni up to the concentration of $y=0.35$, see Table 3 and Fig. 4, panel b.

The total occupation of the octahedral sites (Fig. 5) with the increase in $\mathrm{Cu}$ concentration in both $\mathrm{Cu}_{x} \mathrm{Ni}_{0.1} \mathrm{TiSe}_{2}$ and $\mathrm{Cu}_{x-}$ $\mathrm{Ni}_{0.25} \mathrm{TiSe}_{2}$ systems remains constant and approximately equals to the occupation of the octahedral sites by the $\mathrm{Ni}$ atoms in $\mathrm{Ni}_{0.1} \mathrm{TiSe}_{2}$ and $\mathrm{Ni}_{0.25} \mathrm{TiSe}_{2}$. This is probably due to the minimization of the energy of elastic deformation, because the co-intercalation affects the lattice parameters only minimally.

Both $\mathrm{Ni}$ and $\mathrm{Cu}$ atoms can occupy the tetrahedral sites, therefore one can expect the same position of these atoms in the Se tetrahedron, because the ionic radii of $\mathrm{Cu}$ and $\mathrm{Ni}$ are nearly the same. However, their different electronic configuration makes them to have different $z$ coordinates in the Se tetrahedron. In both systems $(y=0.1$ and $y=0.25)$, the $\mathrm{Cu}$ atoms are located closer to the base of the tetrahedron (the face parallel to the (001) plane) $(z \approx 0.62)$ and the $\mathrm{Ni}$ atoms are closer to the opposite vortex $(z \approx 0.42)$ (Tables $1-3)$.

\section{XPS}

Core level XPS provides insight into the charge state of the atoms. In addition, XPS can be used as a homogeneity test for 

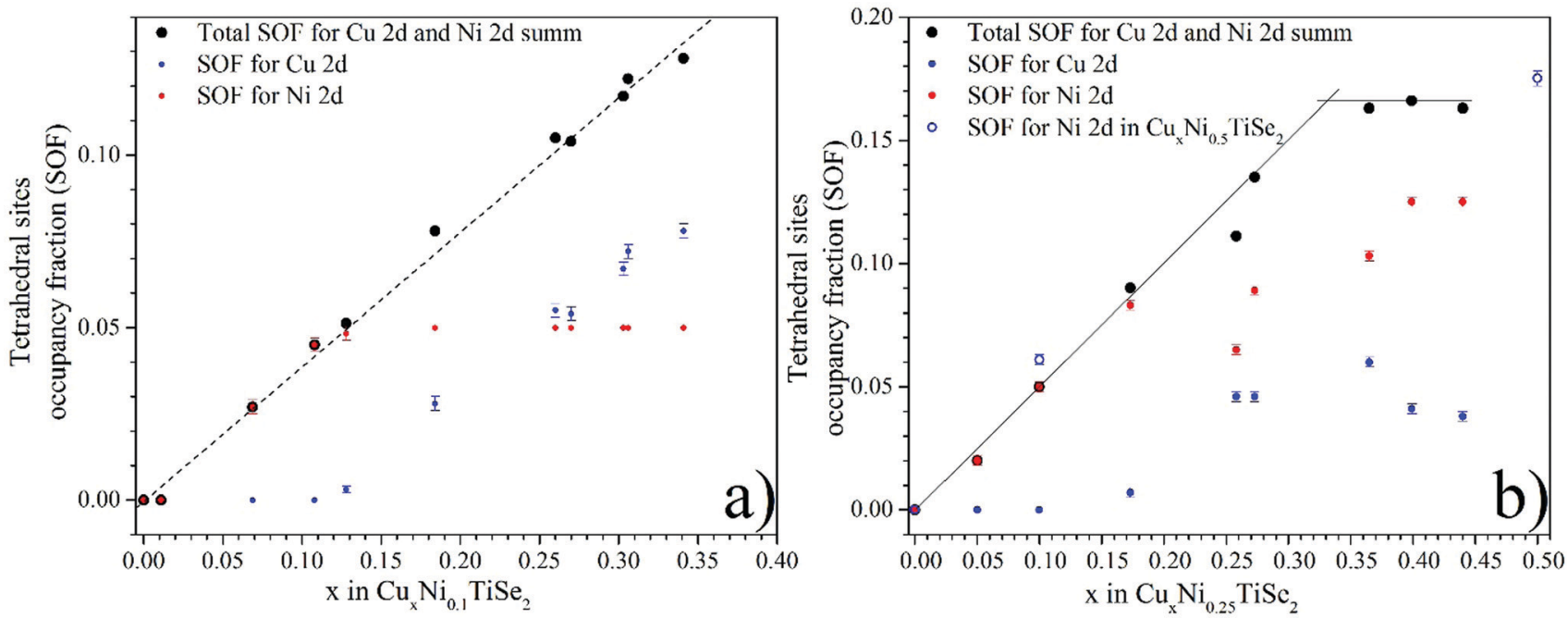

Fig. 4 Occupation of the tetrahedral (2d) sites in the interlayer space by the $\mathrm{Ni}$ and $\mathrm{Cu}$ atoms for $\mathrm{Cu}_{x} \mathrm{Ni}_{y} \mathrm{TiSe} \mathrm{S}_{2}(y=0.1-$ panel a, $y=0.25-$ panel b).
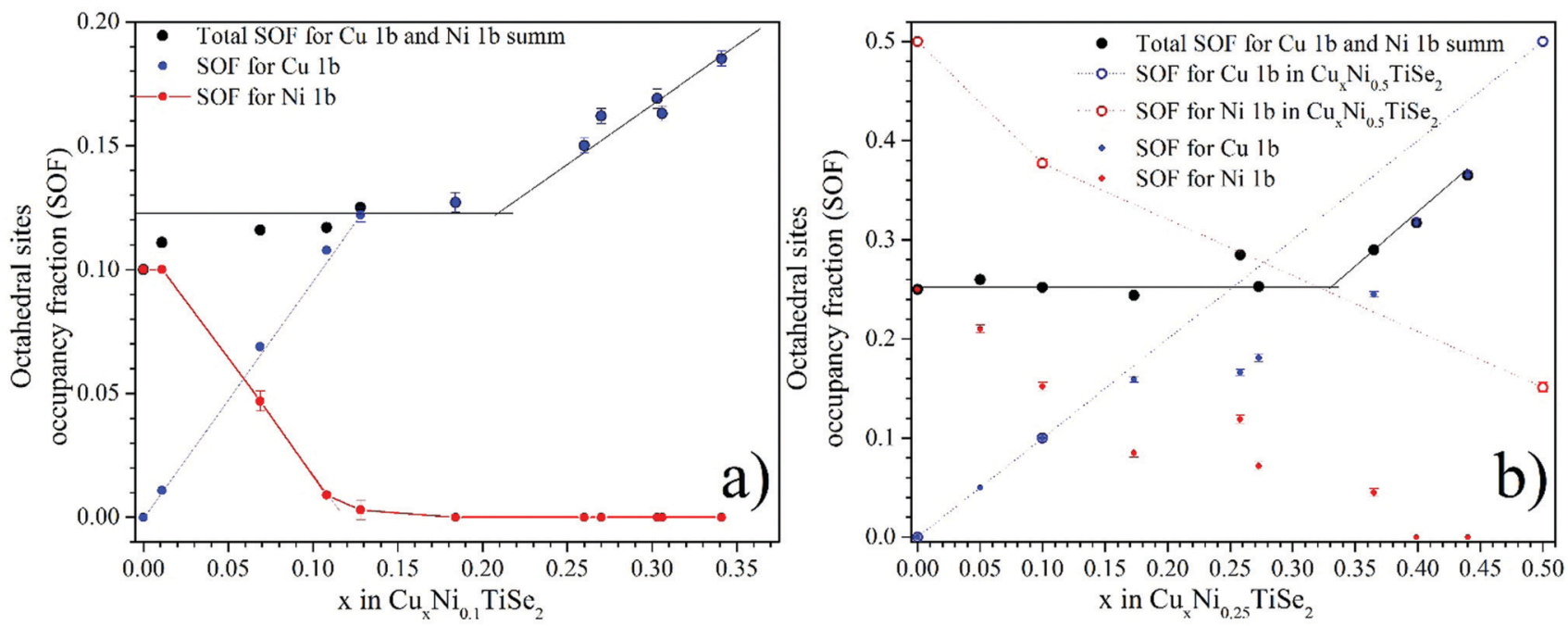

Fig. 5 Occupation of the octahedral (1b) sites in the interlayer space by $\mathrm{Ni}$ and $\mathrm{Cu}$ for $\mathrm{Cu}_{x} \mathrm{Ni}_{y} \mathrm{TiSe}_{2}(y=0.1-$ panel $\mathrm{a}, y=0.25-$ panel b).

the studied samples. The Se 3d spectra (Fig. 6) are specially sensitive to the changes in phase composition and surface quality. $^{20,25}$

Even at low Ni concentration $(x=0.14)$, a shift towards higher binding energies is observed (see Table 4). According to ref. 19, two Ni concentration ranges can be distinguished in $\mathrm{Ni}_{x} \mathrm{TiSe}_{2}$, in which the Se $3 \mathrm{~d}$ binding energy slightly changes: low $\mathrm{Ni}$ concentrations (at $x<0.25$ the $\mathrm{Ni}$ atoms can be considered as isolated ones), and high $\mathrm{Ni}$ concentrations (above $x=0.25$, which corresponds to the percolation threshold of the Ti atoms coordinated by Ni). As it can be seen in Fig. 6 and Table 4, the $\mathrm{Cu}$ intercalation into $\mathrm{Ni}_{y} \mathrm{TiSe}_{2}$ leads to a further shift of the Se $3 \mathrm{~d}$ line toward the higher binding energies. This is in good agreement with previously obtained data for the $\mathrm{Cu}_{x} \mathrm{TiSe}_{2}$ system for $x<0.2$, where $\mathrm{Cu}$ intercalation also did not affect the shift of the Se $3 \mathrm{~d}$ line..$^{20}$ Probably, the increase in the Se $3 \mathrm{~d}$ binding energy is not the result of an electron transfer from $\mathrm{Cu}$ to the lattice, but the result of redistribution of the $\mathrm{Ni}$ atoms due to the $\mathrm{Cu}$ intercalation.

The Se $3 d$ line width is sensitive to the distribution of the $\mathrm{Ni}$ atoms over the octahedral and tetrahedral sites. Indeed, for $\mathrm{Cu}_{0.13} \mathrm{Ni}_{0.43} \mathrm{TiSe}_{2}$, which is close to $\mathrm{Cu}_{0.1} \mathrm{Ni}_{0.5} \mathrm{TiSe}_{2}$, almost all the $\mathrm{Ni}$ atoms are in the octahedral sites, and the Se $3 \mathrm{~d}$ line is just slightly broader than that for $\mathrm{Ni}_{0.46} \mathrm{TiSe}_{2}$. In its turn, in $\mathrm{Ni}_{0.46} \mathrm{TiSe}_{2}$ all of the $\mathrm{Ni}$ atoms occupy only the octahedral sites, whereas in $\mathrm{Cu}_{0.2} \mathrm{Ni}_{0.25} \mathrm{TiSe}_{2}$ the $\mathrm{Ni}$ atoms are nearly equally distributed between the octahedral and tetrahedral sites (see Fig. 3, panel a), and the Se 3d line becomes broad and its double-peak structure cannot be observed. Considering the site occupancy fractions of the octa- and tetrahedral sites (see Table $2, \mathrm{SOF}=0.244$ for $1 \mathrm{~b}$ sites, $\mathrm{SOF}=0.173$ for $2 \mathrm{~d}$ sites) we can assume that in $\mathrm{Cu}_{0.2} \mathrm{Ni}_{0.25} \mathrm{TiSe}_{2}$ the Se $3 \mathrm{~d}$ states with higher binding (dark green dashed line, Fig. 6) are due to the Se atoms forming the octahedrons, while those with lower binding 


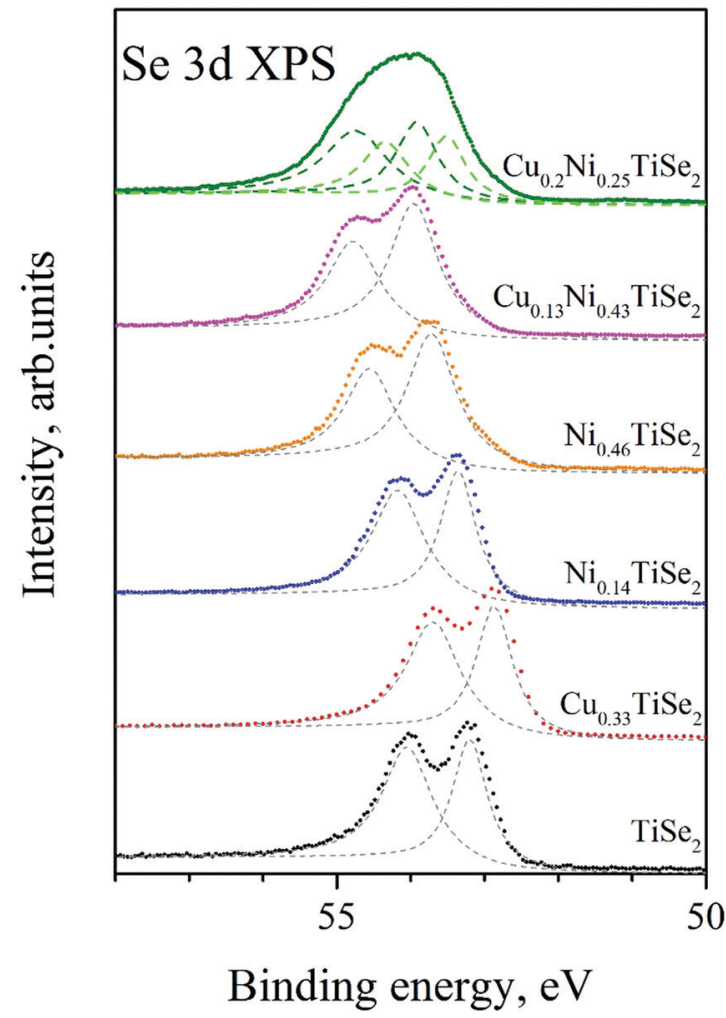

Fig. 6 The Se 3d spectra for $\mathrm{Cu}_{x} \mathrm{Ni}_{y} \mathrm{TiSe} e_{2}$. The Se $3 d$ spectra for monointercalated $\mathrm{Cu}_{x} \mathrm{TiSe}_{2}$ and $\mathrm{Ni}_{y} \mathrm{TiSe}_{2}$ are shown as well.

energies (light green dashed line, Fig. 6) are due to the Se atoms forming the tetrahedrons.

The Ti $2 p$ spectra are shown in Fig. 7. They are similar to those for the $\mathrm{Ni}_{y} \mathrm{TiSe}_{2}$ system. ${ }^{19}$ The second (with higher binding energy) Ti state appears due to the presence or absence of intercalated atoms in the second coordination sphere of $\mathrm{Ti}$ atoms. This is in a good agreement with the fact that the change in the $\mathrm{Cu}$ concentration in $\mathrm{Cu}_{x} \mathrm{TiSe}_{2}$ did not affect the Ti 2 p spectra. ${ }^{20}$

The $\mathrm{Cu} 2 \mathrm{p}$ spectra shown in Fig. 8 (left panel) are almost identical to those for the $\mathrm{Cu}_{x} \mathrm{TiSe}_{2}$ system ${ }^{20}$ and correspond to the $\mathrm{Cu}^{0}$ or $\mathrm{Cu}^{\mathrm{I}}$ charge state. This is not surprising since the $\mathrm{Cu}$ atoms occupy identical octahedral sites in all of these compounds.
The binding energy of the Ni 2p state (Fig. 8, right panel) does not depend on the $\mathrm{Ni}$ or $\mathrm{Cu}$ concentration (Table 4). However, a change in the shape of the $\mathrm{Ni} 2 \mathrm{p}$ spectrum is observed. With the increase in the $\mathrm{Cu}$ concentration, the intensity of a satellite (marked as Sh in Fig. 8) significantly decreases.

\section{XAS}

The X-ray absorption spectra provide information regarding the ratio of the ionic and covalent contribution to the chemical bond of the selected atom. ${ }^{26}$ This characteristic is related to the local arrangement of the selected atoms and their nearest neighbors; therefore, it should be sensitive to the crystal field effects.

The Ti $\mathrm{L}_{2.3}$ absorption spectra are shown in Fig. 9, left panel. A change in the $\mathrm{Cu}$ concentration does not affect the shape and energy position of $\mathrm{Ti} \mathrm{L}_{2.3} \mathrm{XAS}$, as in the case of the Ti $2 \mathrm{p}$ corelevel spectra. The Ti $\mathrm{L}_{2.3}$ absorption spectra can be divided into two groups: the first group for the compounds with low $\mathrm{Ni}$ concentration $(x<0.25)$, the second one for the compounds with high Ni concentration $(x \geq 0.25)$. The difference in the Ti coordination in these groups is related to the different influence of the neighboring Se atoms. In $\mathrm{Ni}_{0.46} \mathrm{TiSe}_{2}$ the ordering of $\mathrm{Ni}$ resulting in the monoclinic structure is observed. This distorts the Se sublattice and, consequently, leads to a change in the coordination of the Ti atoms by the Se ones..$^{24}$ Another way to distort the Se sublattice is redistribution of the Ni atoms between the octa- and tetrahedral sites caused by the $\mathrm{Cu}$ intercalation. This distortion can change the local crystal field around $\mathrm{Ti}$ atoms and influence the lineshape of $\mathrm{Ti} \mathrm{L}_{2.3}$ XAS.

The $\mathrm{Cu} \mathrm{L} \mathrm{L}_{2.3}$ absorption spectra are shown in Fig. 9, right panel. As one can see, $\mathrm{Cu} \mathrm{L}_{2.3} \mathrm{XAS}$ for $\mathrm{Cu}_{0.13} \mathrm{Ni}_{0.43} \mathrm{TiSe}_{2}$ is almost identical to that for $\mathrm{Cu}_{0.33} \mathrm{TiSe}_{2}$ without $\mathrm{Ni}$ intercalation. As the $\mathrm{Cu}$ concentration increases $\left(\mathrm{Cu}_{0.2} \mathrm{Ni}_{0.25} \mathrm{TiSe}_{2}\right)$, the lineshape changes; additional bands marked with arrows in Fig. 9 appear. In $\mathrm{Cu}_{0.13} \mathrm{Ni}_{0.43} \mathrm{TiSe}_{2}$, which is close in chemical composition to $\mathrm{Cu}_{0.1} \mathrm{Ni}_{0.5} \mathrm{TiSe}_{2}$, all of the $\mathrm{Cu}$ atoms occupy the octahedral sites, as in the $\mathrm{Cu}_{x} \mathrm{TiSe}_{2}$ compounds. Although in $\mathrm{Cu}_{0.2} \mathrm{Ni}_{0.25} \mathrm{TiSe}_{2}$ the $\mathrm{Cu}$ atoms also mostly occupy the octahedral sites, some of them occupy the tetrahedral sites. Therefore, these additional XAS features can be associated with the $\mathrm{Cu}$ atoms in the tetrahedral sites.

The Ni $\mathrm{L}_{2.3}$ absorption spectra (Fig. 10) substantially depend on the $\mathrm{Cu}$ concentration. $\mathrm{Cu}$ intercalation into $\mathrm{Ni}_{y} \mathrm{TiSe}_{2}$ changes

Table 4 Results of the fitting of XPS spectra. Se $3 d_{5 / 2}$, Ti $2 p_{3 / 2}$ and Ni $2 p_{3 / 2}$ - the energy positions of the corresponding core levels. Ti $L_{3}(A)$ and $T i L_{3}(B)-$ the energy position of the $A$ and $B$ peaks in the absorption spectra (Fig. 9). $V B_{T}$ and $V B_{R}$ - the energy positions of the $T$ and $R$ peaks in the valence band spectra (Fig. 11), $I_{T}$ and $I_{R}-$ intensities of the $T$ and R peaks (Fig. 11)

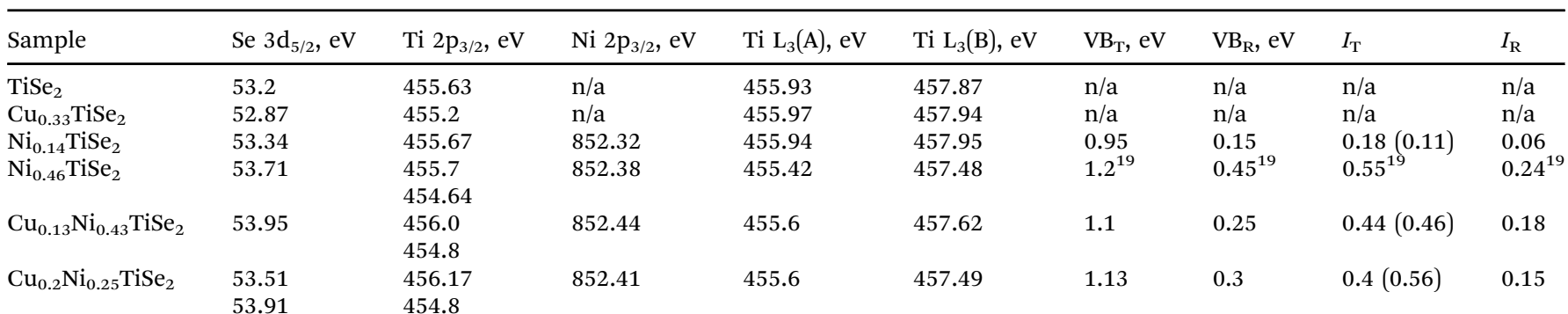




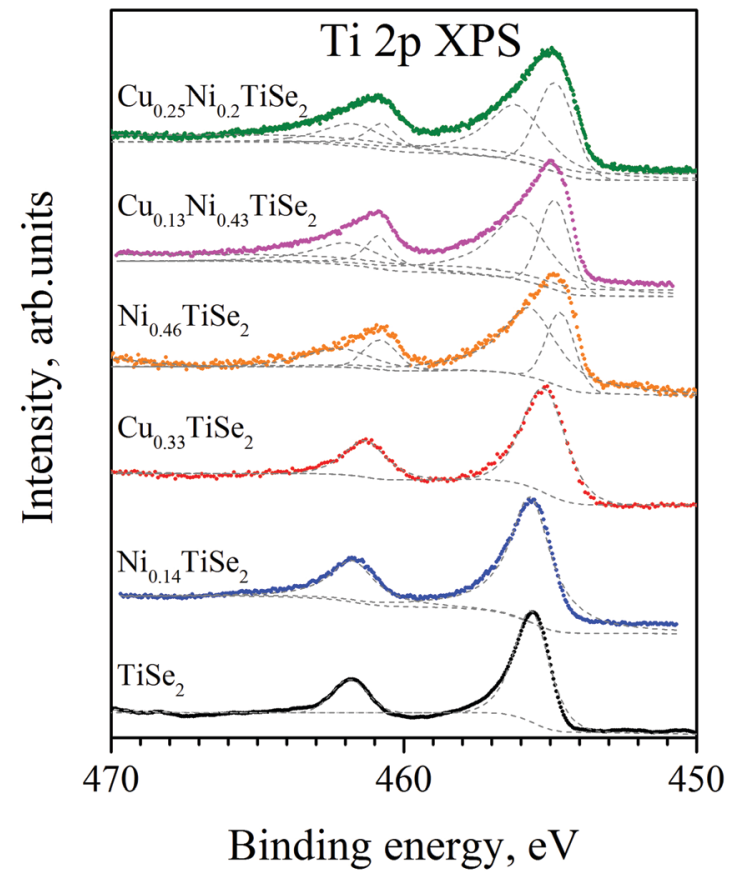

Fig. 7 The Ti $2 p$ spectra for $\mathrm{Cu}_{x} \mathrm{Ni}_{y} \mathrm{TiSe}_{2}$. The Ti $2 p$ spectra for monointercalated $\mathrm{Cu}_{x} \mathrm{TiSe}_{2}$ and $\mathrm{Ni}_{y} \mathrm{TiSe}_{2}$ are shown as well.

the lineshape. The $\mathrm{Ni}$ atoms in $\mathrm{Ni}_{0.14} \mathrm{TiSe}_{2}$ occupy the octahedral sites only. In $\mathrm{Cu}_{0.13} \mathrm{Ni}_{0.43} \mathrm{TiSe}_{2}\left(\mathrm{Cu}_{0.1} \mathrm{Ni}_{0.5} \mathrm{TiSe}_{2}\right)$, the $\mathrm{Ni}$ atoms occupy mainly the octahedral sites, whereas in $\mathrm{Cu}_{0.2} \mathrm{Ni}_{0.25} \mathrm{TiSe}_{2}$ they are equally distributed over the octahedral and tetrahedral sites. Two different coordination of the $\mathrm{Ni}$ atoms result in a broadening of the $\mathrm{Ni} \mathrm{L}_{2.3}$ absorption spectrum for $\mathrm{Cu}_{0.2} \mathrm{Ni}_{0.25} \mathrm{TiSe}_{2}$ $(\mathrm{FWHM}=1.7 \mathrm{eV})$ as compared to that for $\mathrm{Cu}_{0.13} \mathrm{Ni}_{0.43} \mathrm{TiSe}_{2}$
$($ FWHM $=1.5 \mathrm{eV})$ (see the inset in Fig. 10). Moreover, there is a pronounced difference between the shapes of the $\mathrm{Ni} \mathrm{L}_{3.2}$ XAS spectra for $\mathrm{Ni}_{0.14} \mathrm{TiSe}_{2}$ and $\mathrm{Cu}_{x} \mathrm{Ni}_{y} \mathrm{TiSe}_{2}$. This difference can be related to the different crystal field around $\mathrm{Ni}$ atoms in the tetrahedral sites.

\section{Valence band}

The photoemission spectra of the valence band (VB) provide insight into the state of the valence electrons that are responsible for the chemical bonds in the material. The use of excitation radiation with a resonant energy close to the $2 \mathrm{p}-3 \mathrm{~d}$ transition energy allows for determination of the partial atomic contributions in the density of states in the valence band. The VB spectra for $\mathrm{Cu}_{x} \mathrm{Ni}_{y} \mathrm{TiSe}_{2}$ are shown in Fig. 11.

The VB spectra for $\mathrm{Cu}_{x} \mathrm{Ni}_{y} \mathrm{TiSe}_{2}$ differ from those for TiSe by the presence of $\mathrm{T}$ and $\mathrm{R}$ peaks near the Fermi level. Both of these peaks are typical for the $\mathrm{Ni}_{x} \mathrm{TiSe}_{2}$ system. ${ }^{19}$ One can see that the intensity of the $\mathrm{T}$ peak increases with $\mathrm{Ni}$ concentration. The intensity of the $\mathrm{R}$ peak also increases with $\mathrm{Ni}$ concentration but does not depend on the $\mathrm{Cu}$ concentration (Table 4). However, for all the studied compounds $\mathrm{Cu}_{x} \mathrm{MeCh}_{2}$ $(\mathrm{Me}=\mathrm{Ti}, \mathrm{Zr} ; \mathrm{Ch}=\mathrm{S}, \mathrm{Se}, \mathrm{Te}) \mathrm{Cu}$ states are not observed near the Fermi level. ${ }^{27,28}$ To clarify the partial contribution to the states near the Fermi level, the resonant photoemission spectroscopy was used. ${ }^{29-32}$ The valence band spectra for $\mathrm{Cu}_{x} \mathrm{Ni}_{y} \mathrm{TiSe}_{2}$ obtained in the $\mathrm{Ti} 2 \mathrm{p}_{3 / 2}-3 \mathrm{~d}$ resonant excitation mode are shown in Fig. 12.

One can see that the $\mathrm{Cu}$ intercalation into $\mathrm{Ni}_{y} \mathrm{TiSe}_{2}$ leads to an increase in the intensity of the resonant line directly at the Fermi level. This effect can be explained as a result of the filling of the $\mathrm{Ti} 3 \mathrm{~d}$ conduction band. We can conclude that the $\mathrm{Cu}$ intercalation in both $\mathrm{TiSe}_{2}$ and $\mathrm{Ni}_{y} \mathrm{TiSe}_{2}$ leads to the charge
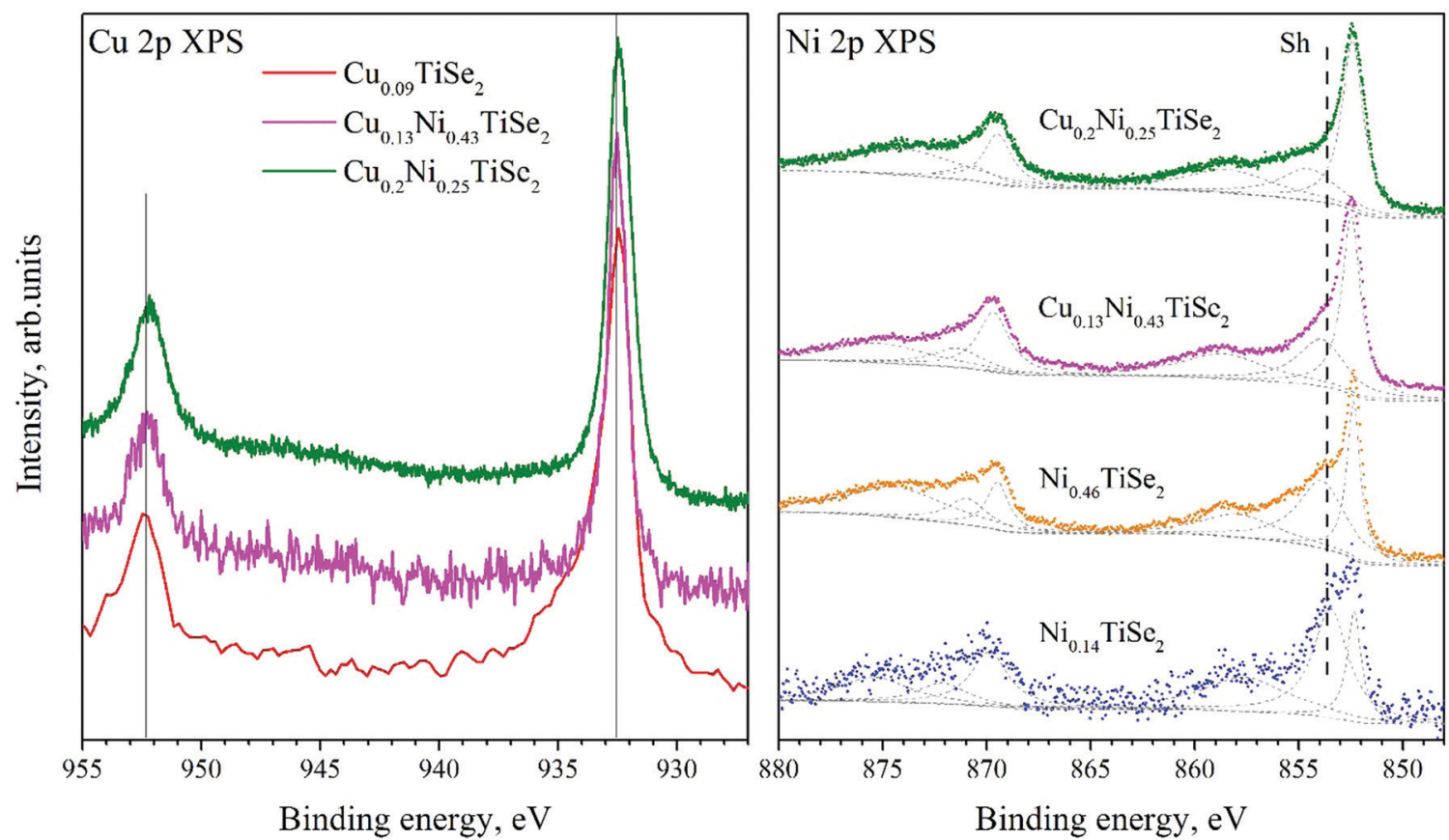

Fig. 8 The Cu $2 p$ spectra for $\mathrm{Cu}_{x} \mathrm{Ni}_{y} \mathrm{TiSe}_{2}$ and $\mathrm{Cu}_{0.09} \mathrm{TiSe}_{2}$ (left panel). The Ni $2 p$ spectra for $\mathrm{Cu}_{x} \mathrm{Ni}_{y} \mathrm{TiSe}_{2}$ and $\mathrm{Ni}_{y} \mathrm{TiSe}{ }_{2}$ (right panel). 

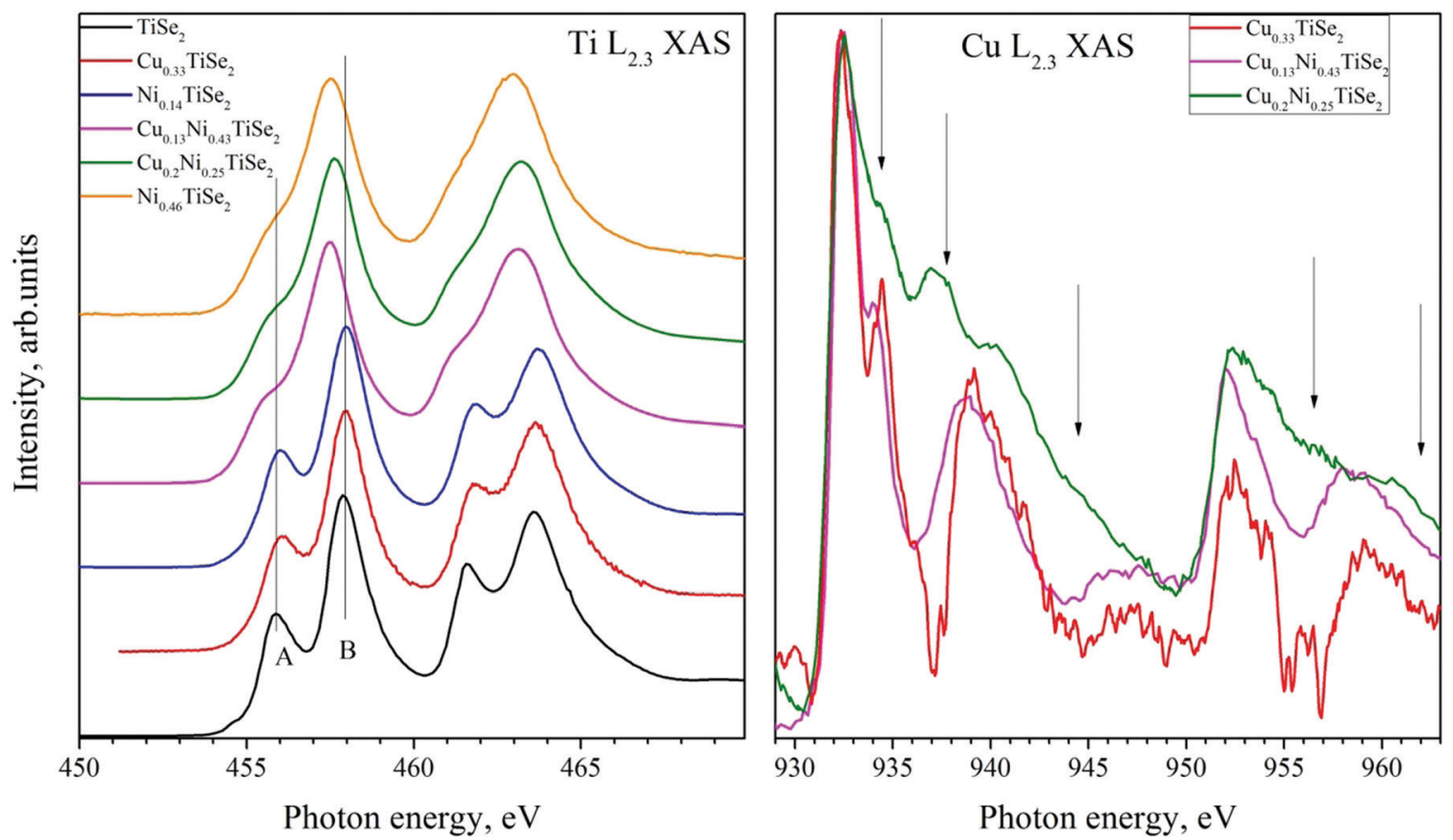

Fig. 9 Ti $\mathrm{L}_{2.3}$ XAS for $\mathrm{Cu}_{x} \mathrm{Ni}_{y} \mathrm{TiSe}_{2}$ (left panel). $\mathrm{Cu} \mathrm{L}_{2.3}$ XAS for $\mathrm{Cu}_{x} \mathrm{Ni}_{y} \mathrm{TiSe}_{2}$ (right panel).

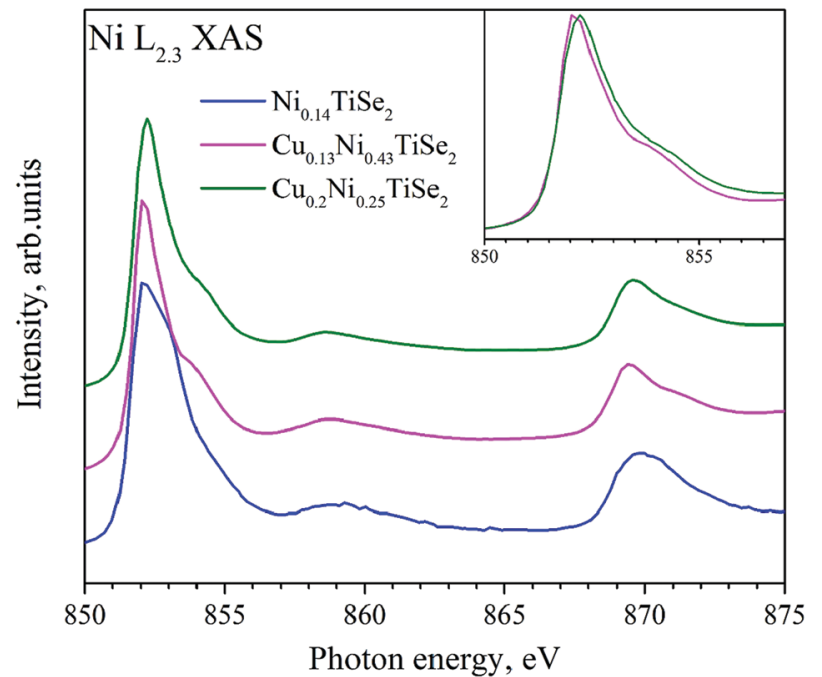

Fig. $10 \mathrm{Ni} L_{2.3}$ XAS for $\mathrm{Cu}_{x} \mathrm{Ni}_{y} \mathrm{TiSe}_{2}$. The inset shows $\mathrm{Ni} L_{3} \mathrm{XAS}$ for $\mathrm{Cu}_{0.13} \mathrm{Ni}_{0.43} \mathrm{TiSe}_{2}$ and $\mathrm{Cu}_{0.2} \mathrm{Ni}_{0.25} \mathrm{TiSe}_{2}$.

transfer to the conduction band formed mainly by the Ti $3 \mathrm{~d}$ states.

To obtain additional information about the states near the Fermi level, constant initial state (CIS) spectra are useful. The CIS experiment is carried out by simultaneously varying the photon energy and the photoelectron kinetic energy, i.e. the measurement is performed at constant ionization (or binding) energy. Ti $2 \mathrm{p}_{3 / 2}-3 \mathrm{~d}$ CIS obtained at $E_{\mathrm{b}}=0.15 \mathrm{eV}$ from the ResPES spectra are shown in Fig. 13.

One can see that CIS are almost identical to the lineshape of Ti $\mathrm{L}_{2.3}$ XAS for corresponding samples. For $\mathrm{Ni}_{0.14} \mathrm{TiSe}_{2}$ both

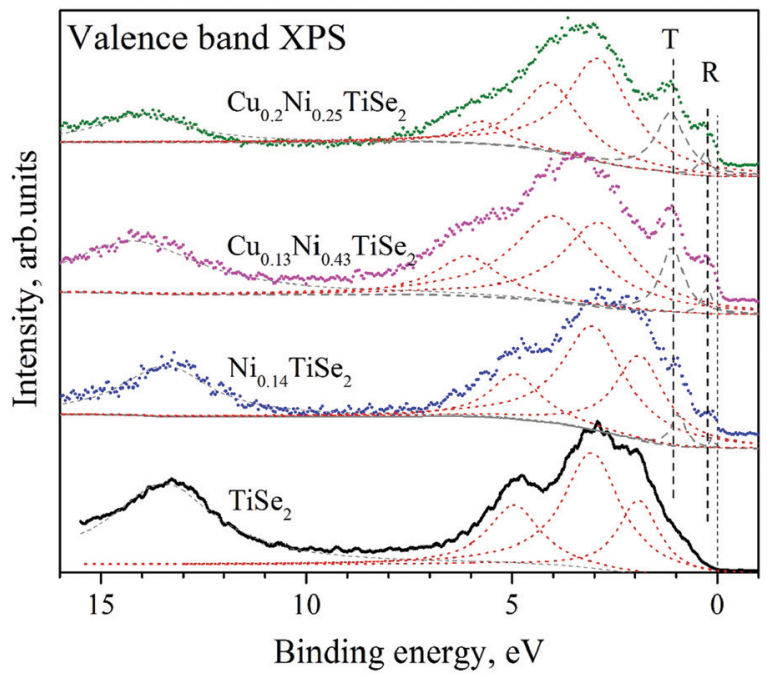

Fig. 11 The valence band spectra for $\mathrm{Cu}_{x} \mathrm{Ni}_{y} \mathrm{TiSe}_{2}$. The excitation energies are as follows: $E_{\text {exc }}=1115 \mathrm{eV}$ for $\mathrm{TiSe}_{2} ; E_{\mathrm{exc}}=848.4 \mathrm{eV}$ for $\mathrm{Ni}_{0.14} \mathrm{TiSe}_{2}$; $E_{\text {exc }}=847.8 \mathrm{eV}$ for $\mathrm{Cu}_{0.13} \mathrm{Ni}_{0.43} \mathrm{TiSe}_{2} ; E_{\text {exc }}=800 \mathrm{eV}$ for $\mathrm{Cu}_{0.2} \mathrm{Ni}_{0.25} \mathrm{TiSe}_{2}$. The peaks typical for $\mathrm{TiCh}_{2}$ are shown with red dots. The $\mathrm{T}$ and $\mathrm{R}$ peaks appearing at the $\mathrm{Cu}$ and $\mathrm{Ni}$ intercalation are shown with gray dashed line.

A and $\mathrm{B}$ peaks are clearly visible, however for $\mathrm{Cu}_{0.13} \mathrm{Ni}_{0.43} \mathrm{TiSe}_{2}$ and $\mathrm{Cu}_{0.2} \mathrm{Ni}_{0.25} \mathrm{TiSe}_{2}$ only the $\mathrm{A}$ peak is well resolved. This allows to associate these $0.15 \mathrm{eV}$-states with $\mathrm{Ti} 3 \mathrm{~d}$ states. Different CIS for $\mathrm{Cu}_{x} \mathrm{Ni}_{y} \mathrm{TiSe}_{2}$ and $\mathrm{Ni}_{y} \mathrm{TiSe}_{2}$ indicate that $\mathrm{Cu}$ intercalation changes the chemical bond of the $\mathrm{Ti}$ atoms. Indeed, it is known that the $\mathrm{Ti} 3 \mathrm{~d}_{z^{2}}$ orbitals hybridize with the nearest neighbors. ${ }^{34}$ Since the Ti $3 \mathrm{~d}_{z^{2}}$ orbital is directed at the octahedral site, it hybridizes with the orbitals of an atom, which is located there. However, the intensity of the resonance 

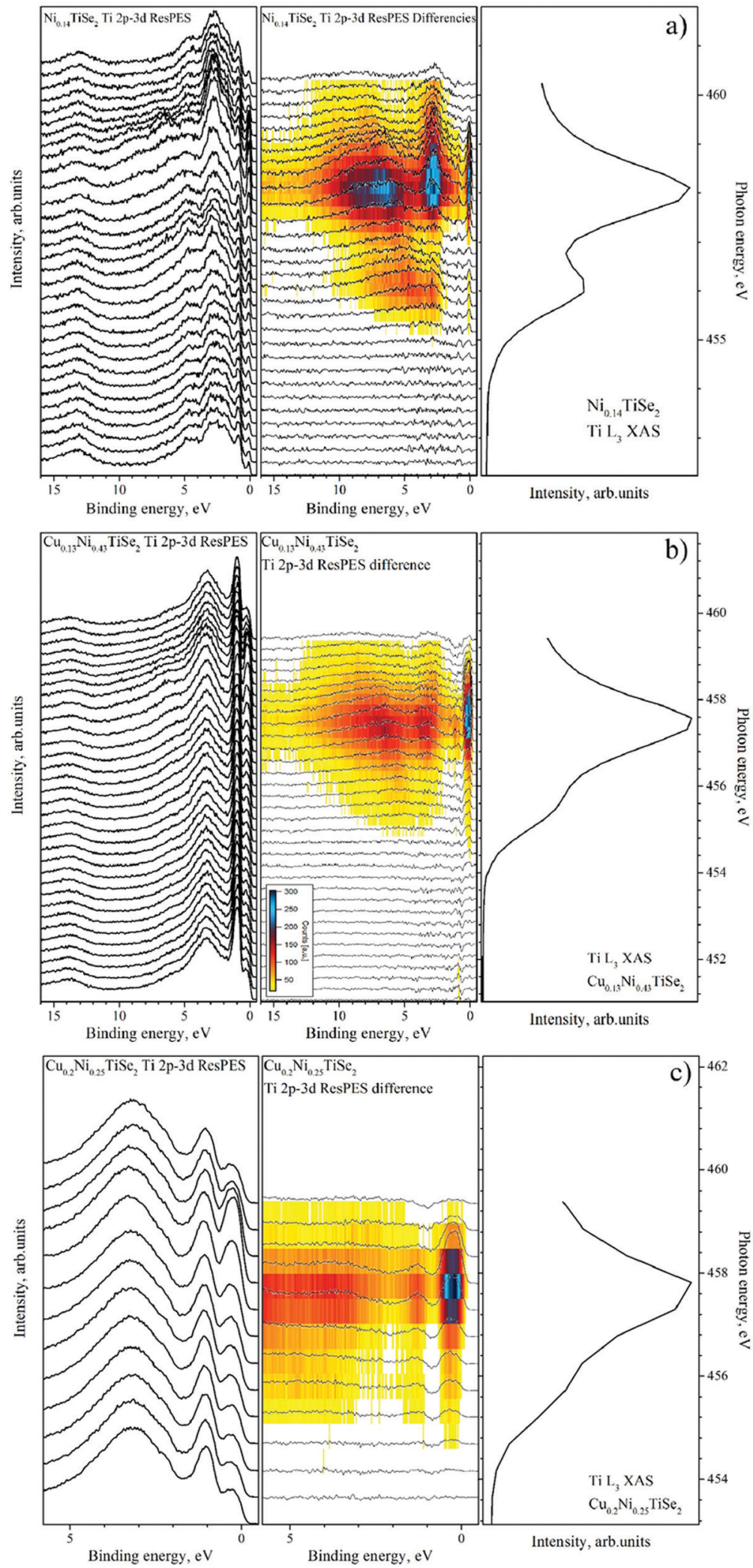

Fig. 12 The valence band spectra obtained in the Ti $2 p_{3 / 2}-3 d$ resonant excitation mode for $\mathrm{Ni}_{0.14} \mathrm{TiSe}_{2}$ (panel a), $\mathrm{Cu}_{0.13} \mathrm{Ni}_{0.43} \mathrm{TiSe}_{2}$ (panel b) and $\mathrm{Cu}_{0.2} \mathrm{Ni}_{0.25} \mathrm{TiSe}_{2}$ (panel c). For all the compounds (from left to right): the VB spectra obtained at different excitation energies; the difference spectra obtained by the subtraction of the off-resonance spectrum from the spectrum at the current excitation energy (as described in ref. 33); the corresponding $\mathrm{Ti}_{3}$ absorption spectrum. 


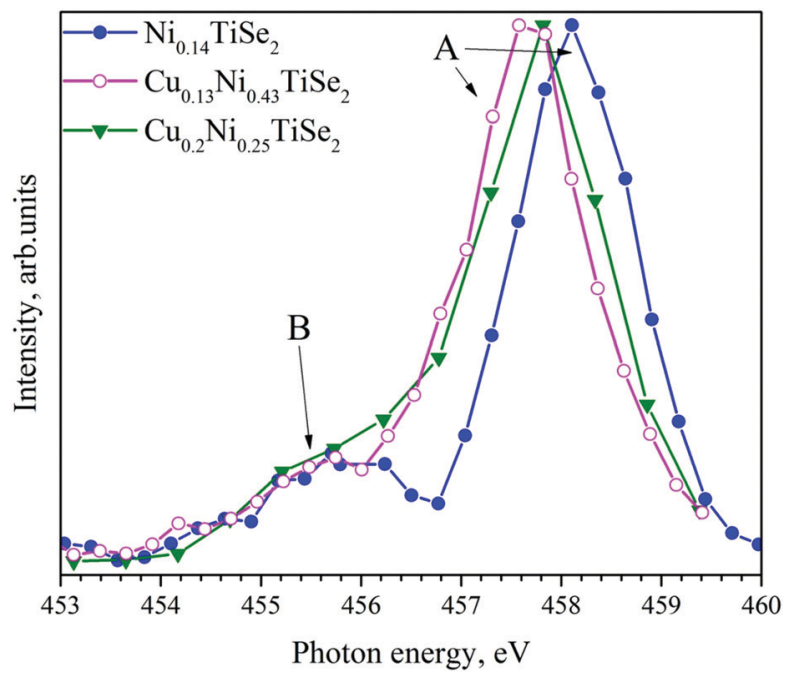

Fig. $13 \mathrm{Ti} 2 \mathrm{p}_{3 / 2}-3 \mathrm{~d} \mathrm{CIS}$ at $E_{\mathrm{b}}=0.15 \mathrm{eV}$ for $\mathrm{Cu}_{x} \mathrm{Ni}_{y} \mathrm{TiSe}_{2}$ obtained from the ResPES spectra.

peak is nearly the same for all studied compounds (Fig. 14, right panel), but its width substantially increases with $\mathrm{Cu}$ intercalation (Fig. 14, left panel). This increase may indicate the appearance of additional hybridized states near the Fermi level.

The VB spectra obtained in the Ni 2p-3d resonant excitation mode are shown in Fig. 15. The main contribution is from the RRAS (resonant Raman Auger spectra) peak; however, after the subtraction of the off-resonance spectrum, a small resonance near the Fermi level both for $\mathrm{Cu}_{x} \mathrm{Ni}_{y} \mathrm{TiSe}_{2}$ and for $\mathrm{Ni}_{0.14} \mathrm{TiSe}_{2}$ can be detected at photon energies slightly beyond the resonant maximum (this peak is marked as $\mathrm{R}$ in Fig. 16, right panel).

\section{Discussion}

The $\mathrm{Cu}$ intercalation into $\mathrm{Ni}_{y} \mathrm{TiSe}_{2}$ led to unintended consequences such as the displacement of the Ni atoms from the octahedral to tetrahedral sites even at room temperature.

It would seem that this displacement of the Ni atoms to the tetrahedral sites by the $\mathrm{Cu}$ ones is probably caused by a Coulomb repulsion. However, the fact that the repulsion effect is observed even at $x<0.12$ (for $y=0.1$ ) and $x<0.17$ (for $y=$ $0.25)$, when the average distances between the intercalated atoms exceeds 18a, indicates, that this interaction occurs involving the host lattice.

The XPS spectra are sensitive to the effective charge of the selected atoms, however no significant changes in the $\mathrm{Cu} 2 \mathrm{p}$ and $\mathrm{Ni} 2 \mathrm{p}$ binding energies with a change in the $\mathrm{Cu}$ concentration are observed; the $\mathrm{Ni}$ and $\mathrm{Cu}$ charge states coincide with those in mono-intercalated compounds. At the same time, there is a sharp decrease in the Ti $2 \mathrm{p}$ binding energy and an increase in the Se 3d binding energy in the core-level spectra for $\mathrm{Cu}_{x} \mathrm{Ni}_{y} \mathrm{TiSe}_{2}$ as compared to those for $\mathrm{Ni}_{y} \mathrm{TiSe}_{2}$. These changes may be caused by the redistribution of the $\mathrm{Ni}$ atoms over the octahedral and tetrahedral sites. As it was shown in ref. 19, the Ni 3d/Ti 3d hybridized band is formed in $\mathrm{Ni}_{y} \mathrm{TiSe}_{2}$ below the Fermi level. This band acts as a trap for the conduction electrons; therefore, the Ni doping does not increase the Fermi energy. The displacement of the $\mathrm{Ni}$ atoms to the tetrahedral sites makes the Ni 3d/Se $4 p$ hybridization possible instead of the Ti 3d/Ni 3d one. To make the Ni-Se chemical bond stable, this hybridized band should lie below the Fermi level. Consequently, the displacement of the $\mathrm{Ni}$ atoms from the octahedral to tetrahedral sites should lead to the "return" of the Ti electrons
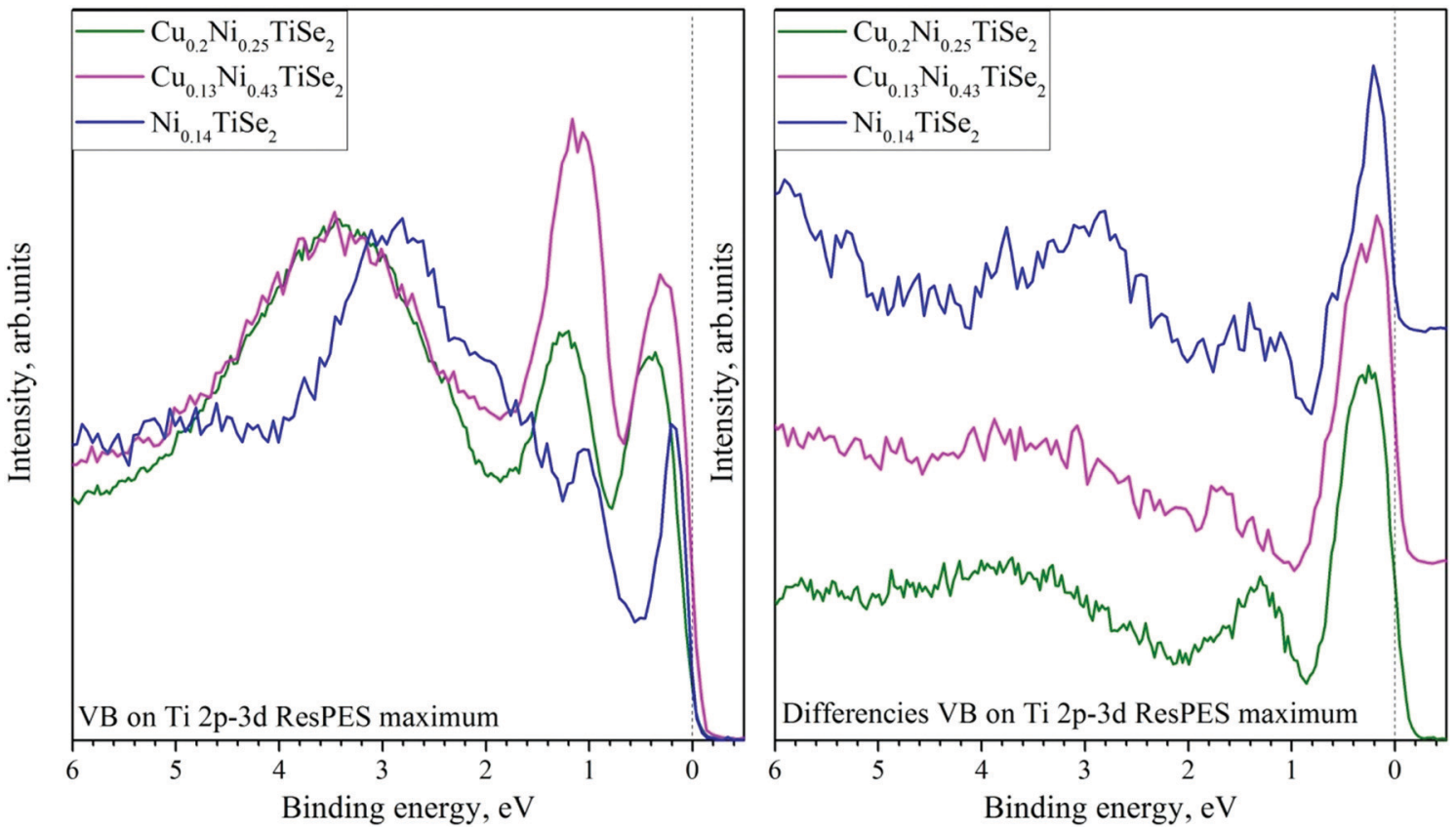

Fig. 14 The on-maximum VB spectra obtained in the $\mathrm{Ti} 2 \mathrm{p}_{3 / 2}-3 \mathrm{~d}$ resonant excitation mode (left panel) and those after off-resonance spectra subtraction (right panel) for $\mathrm{Cu}_{x} \mathrm{Ni}_{y} \mathrm{TiSe}_{2}$. The data processing is described in detail in ref. 33 . 

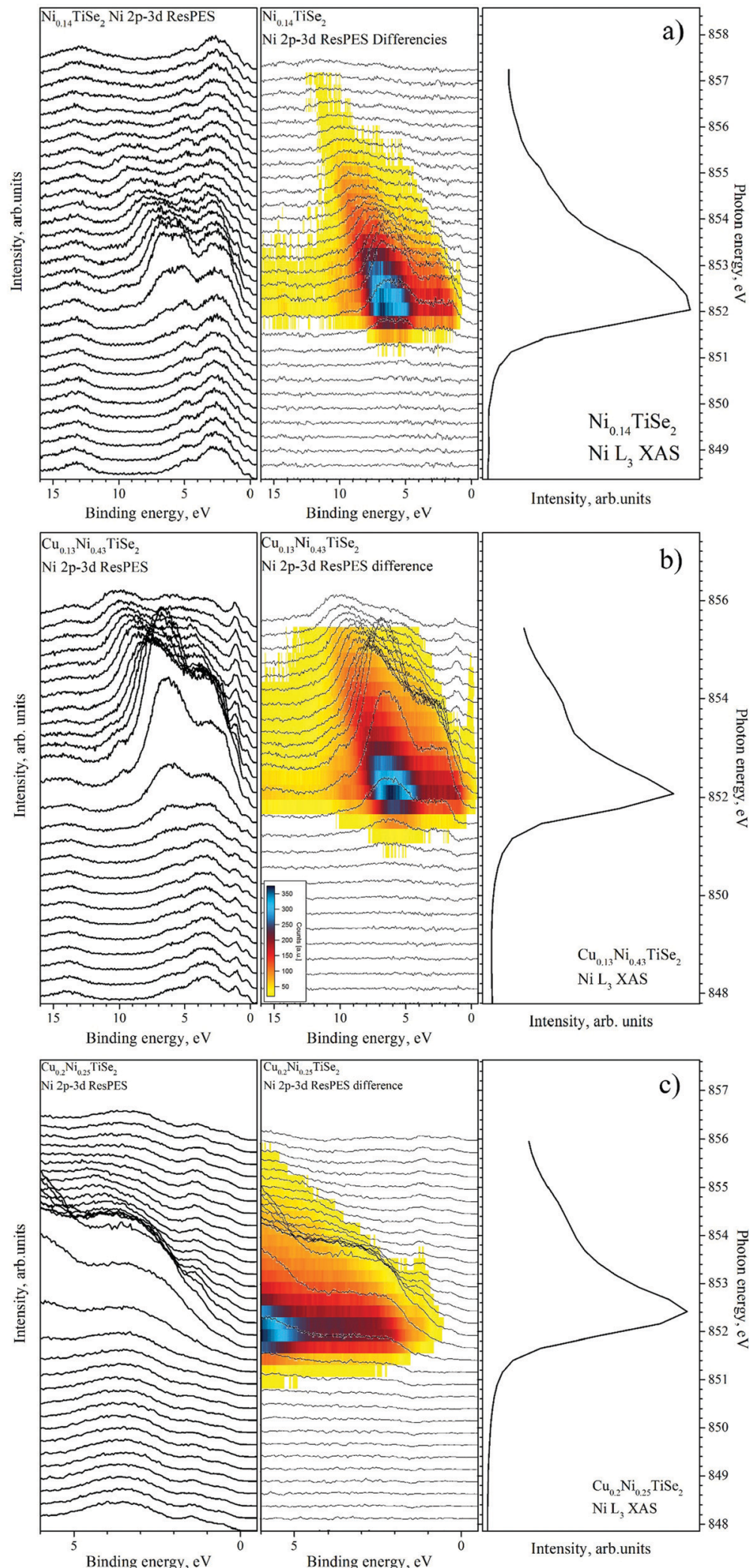

Fig. 15 The VB spectra obtained in the Ni $2 p_{3 / 2}-3 d$ resonant excitation mode for $\mathrm{Ni}_{014} \mathrm{TiSe}_{2}$ (panel a), $\mathrm{Cu}_{0}{ }_{13} \mathrm{Ni}_{0_{43}} \mathrm{TiSe}_{2}$ (panel b) and $\mathrm{Cu}_{0} \mathrm{Ni}_{025} \mathrm{TiSe}_{2}$ (panel c). For all the compounds (from left to right): the VB spectra obtained at different excitation energies; the difference spectra obtained by the subtraction of the on-resonance spectrum from the spectrum at the current excitation energy (as described in ref. 33 ); the corresponding Ni $L_{3}$ absorption spectrum 
participating in the $\mathrm{Ni} 3 \mathrm{~d} / \mathrm{Ti} 3 \mathrm{~d}$ hybridized band and trap the Se electrons participating in the $\mathrm{Ni} 3 \mathrm{~d} / \mathrm{Se} 4 \mathrm{p}$ hybridized band. This should decrease the $\mathrm{Ti}$ and Se effective charges, as indicate the Se $3 \mathrm{~d}$ and Ti 2p core-level spectra (Fig. 6 and 7, respectively, Table 4). This effect involves both $\mathrm{Ni}$ and $\mathrm{Cu}$. The trend of the total $(\mathrm{Ni}+\mathrm{Cu}) \mathrm{SOF}$ for the tetrahedral sites to the constant value of approximately $1 / 6$ indicates this (see Fig. 4, panel b).

An increase in the Se $3 \mathrm{~d}$ binding energy should be associated with a decrease in the effective ionic charge of the selenium. Since both $\mathrm{Ni}$ and $\mathrm{Cu}$ atoms cannot be acceptors, this effect can only be associated with the formation of covalent bonds involving $\mathrm{Ni}$ and/or $\mathrm{Cu}$ states. These covalent centers could play the role of effective acceptors. As can be seen from Fig. 3 (panel b), such states are formed when Ni atoms occupy tetrahedral sites; this results in the broadening of the Se $3 \mathrm{~d}$ line for $\mathrm{Cu}_{0.2} \mathrm{Ni}_{0.25} \mathrm{TiSe}_{2}$ (see Fig. 6 and Table 4).

A joint analysis of the VB spectra obtained in both resonant and non-resonant excitation modes shows that the states forming the $\mathrm{T}$ peak (Fig. 11) are not observed upon Ti $2 \mathrm{p}-3 \mathrm{~d}$ and $\mathrm{Ni} 2 \mathrm{p}-3 \mathrm{~d}$ resonance excitation, although the intensity of this peak changes noticeably. Based on the results of density of states (DOS) calculations for $\mathrm{M}_{x} \mathrm{TiCh}_{2}(\mathrm{M}=3 \mathrm{~d}$ transition metal, $\mathrm{Ch}=\mathrm{S}$, Se, Te), ${ }^{19,25,26,28,36}$ it can be assumed that the band corresponding to the $\mathrm{T}$ peak is formed mainly by the Se states hybridized with the $\mathrm{Ti}$ and $\mathrm{Ni}$ states. The $\mathrm{R}$ peak is clearly visible (Fig. 14 and 16) in the VB spectra obtained both in the Ti $2 \mathrm{p}-3 \mathrm{~d}$ and Ni $2 \mathrm{p}-3 \mathrm{~d}$ resonant excitation modes. This means that both the $\mathrm{Ti} 3 \mathrm{~d}$ and $\mathrm{Ni} 3 \mathrm{~d}$ states form the band resulting in the peak $\mathrm{R}$. This is only possible when the Ni atoms occupy the octahedral sites. Therefore, the $\mathrm{Cu}$ intercalation leading to the displacement of the $\mathrm{Ni}$ atoms to the tetrahedral sites, should decrease the intensity of the $\mathrm{R}$ peak. However, this displacement is accompanied by the donation of $\mathrm{Cu}$ electrons into the Ti 3d state. This increases the intensity of the $\mathrm{R}$ peak, which does not decrease, as it should be upon the displacement of the $\mathrm{Ni}$ atoms to the tetrahedral sites. The $\mathrm{R}$ peak is also observed in the $\mathrm{Ni}_{0.14} \mathrm{TiSe}_{2}$ spectra (see Fig. 11, 12, 15 and 16); however, its intensity is low because the Ti $3 \mathrm{~d}$ states are almost empty. The $\mathrm{Cu}$ intercalation injects electrons to the Ti 3d states and, therefore, should increase the intensity of the $\mathrm{R}$ peak. We observed previously this peak and a similar effect for the $\mathrm{Cu}_{x} \mathrm{TiSe}_{2}$ system. ${ }^{20}$ Thus, the increase in the intensity of the $\mathrm{R}$ peak caused by the filling of the Ti $3 \mathrm{~d}$ states compensates the decrease in the intensity of the $\mathrm{R}$ peak caused by the decreased occupation of the octahedral sites by the Ni atoms.

As follows from the analysis of the XPS and XAS spectra for $\mathrm{Cu}_{x} \mathrm{Ni}_{y} \mathrm{TiSe}_{2}$, the intercalated $\mathrm{Cu}$ atoms donate electrons to the Ti 3d-derived conduction band. This leads to an increase in the Fermi energy; as a result, the Ni $3 \mathrm{~d} / \mathrm{Se} 4 \mathrm{p}$ hybridized band appears below the Fermi level. This is clearly seen comparing the ResPES spectra for $\mathrm{Ni}_{0.14} \mathrm{TiSe}_{2}$ and $\mathrm{Cu}_{0.13} \mathrm{Ni}_{0.43} \mathrm{TiSe}_{2}$, in which $\mathrm{Cu}$ and $\mathrm{Ni}$ atoms occupy the same octahedral sites. However, an increase in the $\mathrm{Cu}$ concentration up to $x=0.2$ in $\mathrm{Cu}_{0.2} \mathrm{Ni}_{0.13} \mathrm{TiSe}_{2}$ leads both to a displacement of the $\mathrm{Ni}$ atoms to the tetrahedral sites and to the disappearance of the filled Ti $3 \mathrm{~d}$ states directly at the Fermi level. Obviously, this depletion of the conduction band is associated with the absorption of electrons by a new hybridized band. Since in the observed $\mathrm{Ni}^{2+}$ charge state only $\mathrm{Ni} 3 \mathrm{~d}_{x z}$ and $\mathrm{Ni} 3 \mathrm{~d}_{y z}$ orbitals directed to the Se atoms remain unfilled, the filling of the Ni $3 \mathrm{~d}$ shell due to the $\mathrm{Cu}$ intercalation leads to the amplification of the interaction between the $\mathrm{Ni}$ and Se atoms. Probably, it is the
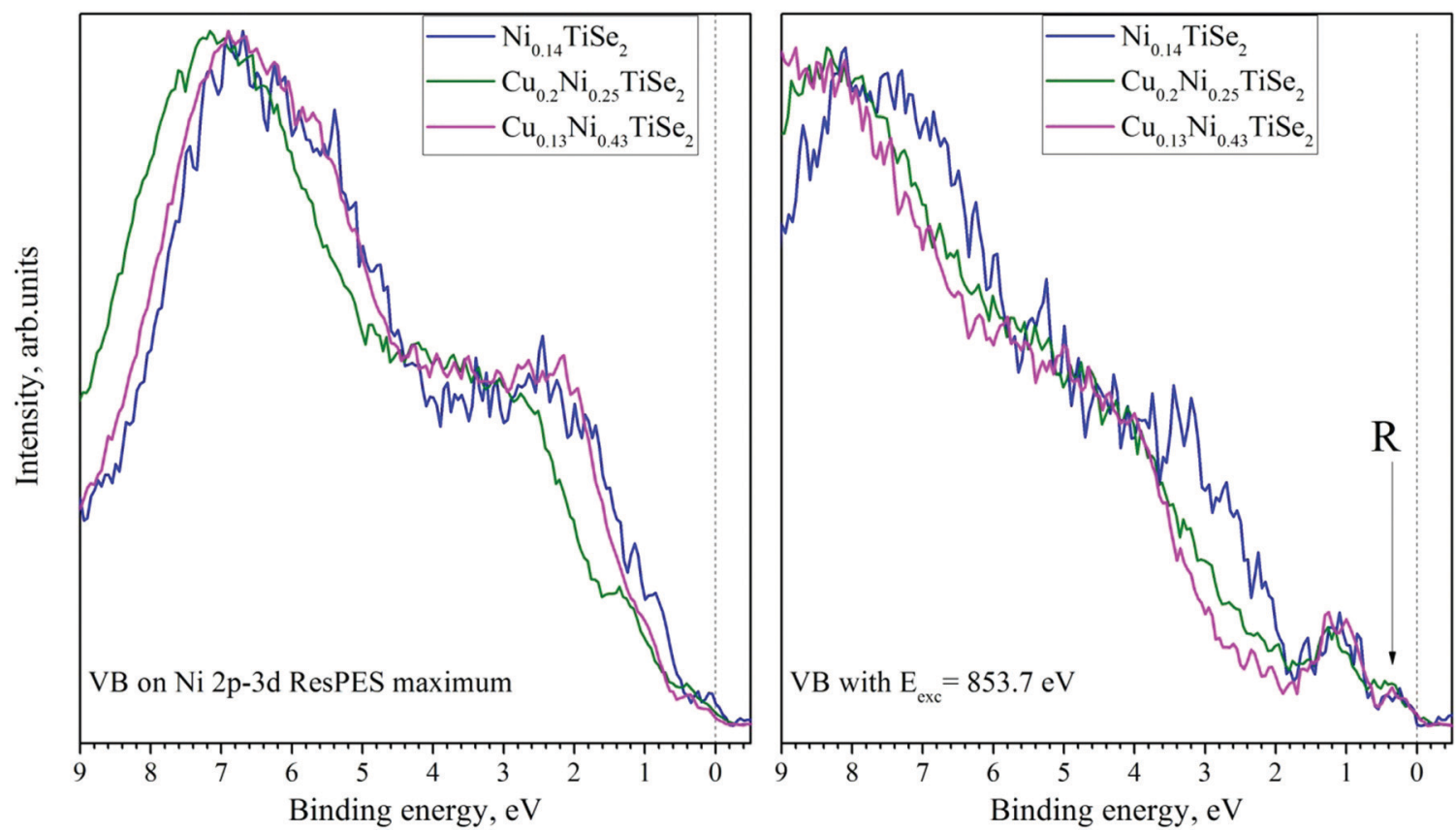

Fig. 16 The on-resonance (left panel) and near-resonance $\left(E_{\text {exc }}=853.7 \mathrm{eV}\right.$ ) (right panel) VB spectra obtained in the Ni $2 \mathrm{p}_{3 / 2}-3 \mathrm{~d}$ resonant excitation mode for $\mathrm{Cu}_{x} \mathrm{Ni}_{y} \mathrm{TiSe}_{2}$ after additional processing (as described in ref. 33 and 35). 
$\mathrm{Ni} 3 \mathrm{~d} / \mathrm{Se} 3 \mathrm{p}$ states that capture the electrons from the $\mathrm{Ti}$ 3d-derived conduction band.

It should be noted that in $\mathrm{Cu}_{x} \mathrm{Ni}_{y} \mathrm{TiSe}_{2}$ the $\mathrm{Cu}$ atoms occupy both tetrahedral and octahedral sites, whereas in monointercalated $\mathrm{Cu}_{x} \mathrm{TiSe}_{2}$ all of the $\mathrm{Cu}$ atoms occupy only the octahedral sites. Unfortunately, we have not succeeded to prepare $\mathrm{Cu}_{x} \mathrm{Ni}_{y} \mathrm{TiSe}_{2}$ single-crystal samples with tetrahedrally coordinated copper. In $\mathrm{Cu}_{0.13} \mathrm{Ni}_{0.43} \mathrm{TiSe}_{2}$ the $\mathrm{Cu}$ atoms occupy the octahedral sites only; in $\mathrm{Cu}_{0.2} \mathrm{Ni}_{0.25} \mathrm{TiSe}_{2}$, the $\mathrm{Cu}$ atoms occupy also the tetrahedral sites, but SOF for these sites is much smaller than that for the octahedral sites. We can assume two possible reasons for the redistribution of the $\mathrm{Cu}$ atoms in $\mathrm{Cu}_{x} \mathrm{Ni}_{y} \mathrm{TiSe}_{2}$ over the tetrahedral and octahedral sites. The first one is a covalent interaction between the $\mathrm{Cu}$ and $\mathrm{Ni}$ atoms involving the host $\mathrm{TiSe}_{2}$ lattice. This is supported by the trend of the total SOF for the tetrahedral sites to a "specific" value of $1 / 6$ (Fig. 4, panel b). The second one is the perturbation of the Se sublattice by the $\mathrm{Ni}$ atoms, which makes the $\mathrm{Cu} 4 \mathrm{p}, 3 \mathrm{~d} / \mathrm{Se} 4 \mathrm{p}$ hybridization in $\mathrm{Cu}_{x} \mathrm{Ni}_{y} \mathrm{TiSe}_{2}$ more energetically favorable than that in $\mathrm{Cu}_{x} \mathrm{TiSe}_{2}$.

It should be noted that the redistribution of the $\mathrm{Ni}$ atoms over the octahedral and tetrahedral sites provides only small changes in the lattice parameters upon the $\mathrm{Cu}$ intercalation. This confirms the previously reported assumption ${ }^{37}$ that the lattice deformation upon intercalation is associated only with the occupation of the octahedral sites. The observed invariance of the lattice parameters (Fig. 2) can be useful for the application in electrochemical devices.

\section{Conclusions}

In this study, the systematic analysis of the crystal and electronic structure of the co-intercalated $\mathrm{Cu}_{x} \mathrm{Ni}_{y} \mathrm{TiSe}_{2}$ system has been performed for the first time. It was found that the $\mathrm{Cu}$ intercalation into $\mathrm{Ni}_{y} \mathrm{TiSe}_{2}$ leads to the displacement of the $\mathrm{Ni}$ atoms from the octahedral to tetrahedral sites. This displacement can be explained by a change in the electronic structure. Being in an octahedral environment $\mathrm{Ni}^{2+}$ has unfilled $\mathrm{d}_{x z}$ and $\mathrm{d}_{y z}$ orbitals oriented to the chalcogen atoms. Being in a tetrahedral environment, Ni has 3 orbitals directed to the chalcogen atoms and 2 orbitals parallel to the basal plane. Obviously, the $\mathrm{Ni}$ atoms should balance between the occupation of octa- and tetrahedral sites; this means, respectively, the balance between the Ni $3 \mathrm{~d} / \mathrm{Ti}$ $3 \mathrm{~d}_{z^{2}} / \mathrm{Se} 3 \mathrm{p}$ (one Ni orbital is hybridized with Ti orbitals and two of them are hybridized with Se orbitals) and Ni 3d/Se 3p (three Ni orbitals are hybridized with Se orbitals) hybridization. An increase in the $\mathrm{Ti} 3 \mathrm{~d}$ band filling makes the $\mathrm{Ni} 3 \mathrm{~d} / \mathrm{Se} 3 \mathrm{p}$ hybridization preferable, probably due to an increase in the Fermi energy and decrease in the energy gain at the Ni 3d/Ti 3d hybridization. Thus, the prediction of the preferred coordination of the intercalated atoms in these compounds should consider the spatial electronic configuration of the d-orbitals of these atoms.

The displacement of the $\mathrm{Ni}$ atoms from the octahedral to tetrahedral sites should also be observed in the case of the intercalation of $\mathrm{Ni}_{y} \mathrm{TiSe}_{2}$ by other donor dopants weakly perturbing the crystal structure of the host lattice. For example, alkali metals fit well for this purpose. As a particular advantage, it can be noted that the displacement of the Ni atoms occurs at room temperature. Therefore, we expect this can be easily obtained by the electrochemical intercalation.

\section{Conflicts of interest}

There are no conflicts to declare.

\section{Acknowledgements}

The research was carried out within the state assignment of Minobrnauki of Russia (theme "Electron" No. AAAA-A18118020190098-5 and theme "Spin" No. AAAA-A18-118020 290104-2) and with partial financial support of the RFBR (project 18-32-20141). This work has been done using facilities of the Shared Service Centre "Ural-M", Institute of Metallurgy of the Ural Branch of the Russian Academy of Sciences. I. P., S. N. and F. B. acknowledge funding from EUROFEL project (RoadMap Esfri). This project has received funding from the EU-H2020 research and innovation program under grant agreement No. 654360 having benefitted from the Access provided by IOM-CNR in Trieste (Italy) within the framework of the NFFA-Europe Transnational Access Activity. We acknowledge the Elettra Sincrotrone Trieste for providing access to its synchrotron radiation facilities and we thank $\mathrm{N}$. Zema for assistance in using beamline CiPo.

\section{References}

1 J. A. Wilson and A. D. Yoffe, Adv. Phys., 1969, 18, 193-335.

2 R. M. White and G. Lucovsky, Solid State Commun., 1972, 11, 1369-1373.

3 C. M. Fang, R. A. de Groot and C. Haas, Phys. Rev. B: Condens. Matter Mater. Phys., 1997, 56, 4455-4463.

4 H. Cercellier, C. Monney, F. Clerc, C. Battaglia, L. Despont, M. G. Garnier, H. Beck, P. Aebi, L. Patthey, H. Berger and L. Forró, Phys. Rev. Lett., 2007, 99, 146403.

5 D. J. Campbell, C. Eckberg, P. Y. Zavalij, H.-H. Kung, E. Razzoli, M. Michiardi, C. Jozwiak, A. Bostwick, E. Rotenberg, A. Damascelli and J. Paglione, Phys. Rev. Mater., 2019, 3, 053402.

6 C. Lian, S.-J. Zhang, S.-Q. Hu, M.-X. Guan and S. Meng, Nat. Commun., 2020, 11, 43.

7 E. Morosan, H. W. Zandbergen, B. S. Dennis, J. W. G. Bos, Y. Onose, T. Klimczuk, A. P. Ramirez, N. P. Ong and R. J. Cava, Nat. Phys., 2006, 2, 544-550.

8 M. Inoue, H. P. Hughes and A. D. Yoffe, Adv. Phys., 1989, 38, 565-604.

9 E. Guilmeau, Y. Bréard and A. Maignan, Appl. Phys. Lett., 2011, 99, 052107.

10 D. Kraft, U. Weiler, Y. Tomm, A. Thissen, A. Klein and W. Jaegermann, Thin Solid Films, 2003, 431-432, 382-386.

11 M. Inoue, M. Koyano, H. Negishi and M. Sasaki, Mol. Cryst. Liq. Cryst. Sci. Technol., Sect. A, 1994, 245, 37-42. 
12 G. A. Takzei, M. V. Gavrilenko, I. I. Sych, P. Esquinazi and L. M. Kulikov, Phys. Solid State, 1997, 39, 1607-1611.

13 V. F. Balakirev and A. A. Titov, Phys. Solid State, 2013, 55, 598-602.

14 A. A. Titov, A. N. Titov, O. V. Bushkova and V. A. Tsurin, Phys. Solid State, 2010, 52, 1577-1584.

15 A. A. Titov, A. N. Titov, S. G. Titova, S. V. Pryanichnikov and D. S. Chezganov, Phys. Solid State, 2017, 59, 145-150.

16 E. G. Shkvarina, A. A. Titov, A. A. Doroschek, A. S. Shkvarin, D. V. Starichenko, J. R. Plaisier, L. Gigli and A. N. Titov, J. Chem. Phys., 2017, 147, 044712.

17 A. C. Larson and R. B. Von Dreele, Doc. LAUR, 1994, 86-748.

18 H. P. B. Rimmington, A. A. Balchin and B. K. Tanner, J. Cryst. Growth, 1972, 15, 51-56.

19 A. S. Shkvarin, Y. M. Yarmoshenko, A. I. Merentsov, Y. M. Zhukov, A. A. Titov, E. G. Shkvarina and A. N. Titov, Phys. Chem. Chem. Phys., 2017, 19, 4500-4506.

20 A. S. Shkvarin, Y. M. Yarmoshenko, M. V. Yablonskikh, A. I. Merentsov, E. G. Shkvarina, A. A. Titov, Y. M. Zhukov and A. N. Titov, J. Chem. Phys., 2016, 144, 074702.

21 M. Zangrando, M. Finazzi, G. Paolucci, G. Comelli, B. Diviacco, R. P. Walker, D. Cocco and F. Parmigiani, Rev. Sci. Instrum., 2001, 72, 1313.

22 J. Libra, KolXPD (Revision 1.8.0 build 61), Kolibrik.net, s.r.o., Žd’ár nad Sázavou, Czech Republic, 2017.

23 E. Prince, International tables for crystallography, ed. A. J. C. Wilson, Kluwer, 2004, vol. 100.

24 Y. Arnaud, M. Chevreton, A. Ahouandjinou, M. Danot and J. Rouxel, J. Solid State Chem., 1976, 18, 9-15.

25 A. S. Shkvarin, Y. M. Yarmoshenko, A. I. Merentsov, I. Píš, F. Bondino, E. G. Shkvarina and A. N. Titov, Inorg. Chem., 2018, 57, 5544-5553.
26 A. S. Shkvarin, Y. M. Yarmoshenko, N. A. Skorikov, M. V. Yablonskikh, A. I. Merentsov, E. G. Shkvarina and A. N. Titov, J. Exp. Theor. Phys., 2012, 114, 150-156.

27 A. S. Shkvarin, A. I. Merentsov, Y. M. Yarmoshenko, M. S. Postnikov, E. G. Shkvarina, E. V. Mostovshchikova, A. A. Titov, I. Pis, F. Bondino, S. A. Uporov, S. Y. Melchakov and A. N. Titov, J. Mater. Chem. C, 2020, 8, 8290-8304.

28 A. S. Shkvarin, A. I. Merentsov, N. Tsud and A. N. Titov, J. Chem. Phys., 2019, 151, 234701.

29 R. Z. Bachrach, Synchrotron Radiation Research: Advances in Surface and Interface Science Techniques, Springer Science \& Business Media, 2012, vol. 1.

30 A. Kay, E. Arenholz, S. Mun, F. J. G. de Abajo, C. S. Fadley, R. Denecke, Z. Hussain and M. A. Van Hove, Science, 1998, 281, 679-683.

31 J.-E. Rubensson, J. Lüning, S. Eisebitt and W. Eberhardt, Appl. Phys. A: Mater. Sci. Process., 1997, 65, 91-96.

32 N. Mårtensson, M. Weinelt, O. Karis, M. Magnuson, N. Wassdahl, A. Nilsson, J. Stöhr and M. Samant, Appl. Phys. A: Mater. Sci. Process., 1997, 65, 159-167.

33 Y. M. Yarmoshenko, A. S. Shkvarin, M. V. Yablonskikh, A. I. Merentsov and A. N. Titov, J. Appl. Phys., 2013, 114, 133704.

34 A. S. Shkvarin, Y. M. Yarmoshenko, A. I. Merentsov, E. G. Shkvarina, A. F. Gubkin, I. Píš, S. Nappini, F. Bondino, I. A. Bobrikov and A. N. Titov, Inorg. Chem., 2020, 59, 8543-8551.

35 S. Hüfner, S.-H. Yang, B. S. Mun, C. S. Fadley, J. Schäfer, E. Rotenberg and S. D. Kevan, Phys. Rev. B: Condens. Matter Mater. Phys., 2000, 61, 12582-12585.

36 E. G. Shkvarina, S. G. Titova, A. N. Titov and A. S. Shkvarin, J. Alloys Compd., 2017, 717, 286-293.

37 A. N. Titov, Phys. Solid State, 2009, 51, 714-720. 